NBER WORKING PAPER SERIES

\title{
ISOLATED CAPITAL CITIES, ACCOUNTABILITY AND CORRUPTION: EVIDENCE FROM US STATES
}

\author{
Filipe R. Campante \\ Quoc-Anh Do \\ Working Paper 19027 \\ http://www.nber.org/papers/w19027
NATIONAL BUREAU OF ECONOMIC RESEARCH
1050 Massachusetts Avenue
Cambridge, MA 02138 \\ May 2013
}

We thank Alberto Alesina, Jim Alt, Dave Bakke, Francesco Caselli, Davin Chor, Thomas Cole, Alan Ehrenhalt, Claudio Ferraz, Jeff Frieden, Ed Glaeser, Josh Goodman, Rema Hanna, David Lauter, David Luberoff, Andrei Shleifer, Rodrigo Soares, Enrico Spolaore, Ernesto Stein, David Yanagizawa-Drott, and Katia Zhuravskaya for many helpful conversations, seminar participants at PUC-Rio, EPGE-FGV, FGV-SP, LIEPP-Sciences Po, the Political Economy Group at LACEA, and the Taubman Center for State and Local Government at Harvard for useful suggestions, Ed Glaeser, Nguyen Phu Binh, Raven Saks, Kristina Tobio, and C. Scott Walker for invaluable help with the data collection, and Siaw Kiat Hau for excellent research assistance. We gratefully acknowledge the Taubman Center for State and Local Government for generous financial support, and the Economics Department at PUC-Rio for its outstanding hospitality throughout much of the period of work on this research (Campante), and the Singapore Management University and its Lee Foundation Research Award for generous support over most of the work on this research (Do). All errors are our own. The views expressed herein are those of the authors and do not necessarily reflect the views of the National Bureau of Economic Research.

NBER working papers are circulated for discussion and comment purposes. They have not been peerreviewed or been subject to the review by the NBER Board of Directors that accompanies official NBER publications.

(C) 2013 by Filipe R. Campante and Quoc-Anh Do. All rights reserved. Short sections of text, not to exceed two paragraphs, may be quoted without explicit permission provided that full credit, including (C) notice, is given to the source. 
Isolated Capital Cities, Accountability and Corruption: Evidence from US States

Filipe R. Campante and Quoc-Anh Do

NBER Working Paper No. 19027

May 2013

JEL No. D72,D73,L82,R12,R23,R50

\begin{abstract}
$\underline{\text { ABSTRACT }}$
We show that isolated capital cities are robustly associated with greater levels of corruption across US states, in line with the view that this isolation reduces accountability, and in contrast with the alternative hypothesis that it might forestall political capture. We then provide direct evidence that the spatial distribution of population relative to the capital affects different accountability mechanisms over state politics: newspaper coverage, voter knowledge and information, and turnout. We also find evidence against the capture hypothesis: isolated capitals are associated with more money in state-level campaigns. Finally, we show that isolation is linked with worse public good provision.
\end{abstract}

Filipe R. Campante

Harvard Kennedy School

79 JFK Street

Cambridge, MA 02138

and NBER

filipe_campante@harvard.edu

Quoc-Anh Do

Department of Economics \& LIEPP

Sciences Po

28 rue des Saints-Peres

Paris 75007, France

quocanh.do@sciences-po.org 


\section{Introduction}

Corruption is widely seen as a major problem, in developing and developed countries alike, and a voluminous literature in the social sciences has tried to come to grips with its determinants and correlates, both at the cross-country level (Rose-Ackerman 1999, Treisman 2007, inter alia) and within countries. This paper pursues the first systematic investigation of a hitherto underappreciated element in this story: the spatial distribution of the population in a given polity of interest. It does so in a context where its importance has long been speculated: US state politics, with its capital cities that are often relatively isolated from major population centers.

The spatial distribution of population relative to the seat of political power might affect the incentives and opportunities for public officials to misuse their office for private gain - in different ways, and in potentially different directions. On the one hand, it may affect accountability: if people are typically more interested in what is more immediately salient, and if what is geographically closer gains salience, then where people are located will potentially matter for the effectiveness of accountability mechanisms such as the media and political participation. After all, the level of media coverage of the behavior of politicians will be affected by their audience's level of interest, and so will the degree of citizen involvement in politics. As a result of this "accountability view", one might expect that the prevalence of corruption would be greater when politicians are ensconced in relatively isolated capital cities.

On the other hand, the spatial distribution of people and economic activity may also affect the degree to which economic interests intersect with government. Physical proximity might facilitate the interplay between the former and the latter, and from this interplay could arise opportunities for corruption and misbehavior, with political power being captured by economic interests. From this "capture view", one might in turn expect that the prevalence of corruption would be lower when politicians are ensconced in relatively isolated capital cities. As it turns out, these competing views have not been tested systematically, which we believe is due to the lack of appropriate measurement tools for the relevant idea of the spatial distribution of population around the capital city.

Our first contribution is to establish a basic stylized fact, in the context of US states, that is very much in line with the accountability view: isolated capital cities are associated with higher levels of corruption. A simple depiction of that can be seen in Figure 1, where corruption is measured, following a long tradition in the literature on corruption in US states, by the average number of federal convictions of public officials for corruption-related crime, relative to population size. This is plotted against a measure of the isolation of a state's capital city, the average log distance of population to the capital (normalized for the geographical size of the state). We see a pattern in which more isolated capital cities are associated with more corruption.

\section{[FIGURE 1 HERE]}

We establish that this is indeed a very robust connection, in spite of the inherently small sample size. 
First, it holds after controlling for a number of possible correlates of corruption highlighted by the extant literature. Second, it remains when we use different measures of corruption, and different measures of the degree of isolation of the capital city. Third, it is indeed related to something specific about capital cities: there is no additional effect of the degree of isolation of the state's largest city. Last but not least, it seems to be about corruption: there is no connection between the isolation of the capital and other types of federal criminal cases, as exemplified by drug offenses. The link is also important from a quantitative perspective: our preferred specification associates a one-standard-deviation decrease in the isolation of the capital city with a reduction of about three-quarters of a standard deviation in corruption - very much consistent across different measures.

Quite importantly, we are able to address the issue of causality. Since the location of the capital city is an institutional choice, and since it might affect the distribution of population, one might worry that the correlation we observe is being driven by omitted variables - namely, some unobserved determinant of corruption that might also affect that choice or how it impacts the distribution of population. Fortunately, the historical record documenting the designation of state capitals provides us with a plausible source of exogenous variation: the location of the geographical centroid of each state.

There is ample evidence that a major concern as of the time when the location of capitals was being chosen was that it be located near "that spot which will be least removed from every part of the empire," as put by James Madison with regard to the federal capital (Zagarri 1987). Consistent with that, we do see that the degree of isolation of the centroid with respect to the state's population is a good predictor of the isolation of the capital city. The location of the centroid (conditional on the state's borders) is also essentially random, relative to the distribution of economic and institutional features affecting the distribution of population. (Indeed, we find evidence that the isolation of the centroid is not correlated with a number of predetermined variables, suggesting that states whose population happens to be highly concentrated around the centroid were not systematically different from those where the centroid is relatively isolated.) We develop instrumental variables based on that location, and complemented by the spatial distribution of land suitability relative to the centroid, which affects the spatial distribution of population while being arguably exogenous with respect to corruption. Using those variables, we find that the effect of an isolated capital city on corruption is again statistically significant when estimated using this strategy - and quantitatively larger than the baseline estimates.

This basic stylized fact is evidently consistent with the view that isolated capital cities affect corruption because they bring about lower accountability. Our second contribution is to provide direct evidence in support of this accountability view. We start by showing evidence that states with isolated capital cities pay systematically higher salaries to their governors. This is reassuring to the extent that, if weaker accountability is the main culprit, it would be surprising if the possibility of greater illegal rents through corruption were not accompanied by greater levels of legitimate rents. However, in order to go deeper into the possible specific mechanisms, we then investigate two different realms of accountability, certainly 
among the most important: the roles of the media and of the electoral process. Our main question of interest is whether they are indeed affected by the spatial distribution of population, along the lines that we have speculated about.

We do find evidence of that sort. When it comes to the media, we show that newspaper-level coverage of state politics (measured by searching content in online editions) is increasing in the concentration of newspaper circulation around the state capital city. We also show some evidence that these micro-level connections aggregate up to the state level: the (circulation-weighted) amount of coverage is greater in states with less isolated capitals. Just as importantly, this is matched by the individual-level patterns: using data from the American National Election Studies, we find that individuals who live farther from the state capital are less informed and display less interest in state politics. In contrast, and quite tellingly, distance to the state capital does not affect the level of interest in politics in general. Whether these patterns are due to media coverage responding to the demands of a given audience, or due to circulation and the degree of individual information responding to the level of coverage - or most likely a combination - there is in any case a connection between isolated capitals and lower levels of media coverage, and of citizens' interest in and knowledge of state politics.

When it comes to electoral accountability, we find evidence that people who live in counties that are closer to the state capital are more likely to turn out in state elections, controlling for county demographics and state fixed effects. We show that this again seems to be about the special role of the capital, as we control for "placebos" such as the distance to the state largest city, or the state centroid. Most crucially, we also find that the effect of distance to the state capital is not present for state elections that coincide with federal polls (especially for president) - years in which one would presume that forces related to state politics would have a lesser impact on turnout.

While the evidence is consistent with the accountability view, it could still be the case that the capture view is also present - and simply being overcome by the accountability forces in the opposite direction. To check for that possibility, we also look at some direct evidence testing the capture view, by focusing on the role of money in state politics. If the isolation of the capital city hindered the capture of politicians by special interests, we would expect that this role would be more limited in states with relatively isolated capitals. As it turns out, we find a positive correlation between isolation and contributions: states with isolated capital cities tend to witness larger amounts of contributions (controlling for population and the size of the economy). This goes exactly against the presumption of the capture view, and could in fact be interpreted as consistent with a scenario in which low levels of accountability due to lower media scrutiny and citizen participation actually facilitate the influence of money in politics.

Finally, we also provide some evidence on whether this pattern of low accountability affects the ultimate provision of public goods. We find that states with isolated capital cities also seem to spend relatively less on things like education, public welfare, and health care, and more on administrative expenditures. That seems in turn associated with lower public good provision, as measured by a combi- 
nation of inputs and outcomes in education and health care. This suggests that low accountability and corruption induced by isolation do have an impact in terms of government performance and priorities.

The potential connections and contrasting views linking the spatial distribution of the population, accountability, and the prevalence of corruption have actually long been noted by observers in the particular context of US state politics. Some have raised the idea that having a capital city that is geographically isolated from the main centers of population is conducive to higher corruption, precisely because the distance would lead to less accountability. Notably, Wilson's (1966) seminal contribution argued that state-level politics was particularly prone to corruption because state capitals are often located outside the major metropolitan centers of the state, and thus face a lower level of scrutiny by citizens. ${ }^{1}$ In the words of Redlich (2006, p. x-xi), referring to the state of New York (with its relatively isolated capital, Albany), state politicians under these circumstances are faced with voters who "have been lulled into a state of mind whereby attention is focused more on national and local government than on state actions." As a result, "it is no accident that state officials in Annapolis, Jefferson City, Trenton, and Springfield [which are state capitals located at some distance from the states' larger metropolitan areas] have national reputations for political corruption." (Maxwell and Winters 2005, p. 3)

Very much in contrast with that view is the longstanding concern, prominently reflected in the historical records regarding the choice of state capitals, with keeping political and economic power at a healthy distance from each other. The fear of capture of political power by economic interests in the states was often cited as a reason to keep the capital city geographically apart from major centers. As put by Shelley (1996, p. 38) when talking about the late 18th century debate over the location of the federal capital, "many Americans were uneasy about the prospect that their capital would be a major commercial center. The republican philosophy expressed in the Declaration of Independence and in the Constitution regarded the centralization of political and economic power as dangerous."

The substantial quantitative literature looking at corruption across US states (e.g. Meier and Holbrook 1992, Fisman and Gatti 2002, Alt and Lassen 2003, Glaeser and Saks 2006), while pointing at factors ranging from education to historical and cultural factors to the degree of openness of a state's political system, has not provided much systematic evidence with respect to population and its spatial distribution. Some studies have found that population size is positively correlated with corruption (e.g. Meier and Holbrook 1992, Maxwell and Winters 2005), although this relationship is not particularly robust - as indicated for instance by Meier and Schlesinger (2002) and Glaeser and Saks (2006). When it comes to the spatial distribution of population, most effort has been devoted to looking at the correlation with the degree of urbanization, under the assumption that corruption tends to thrive in cities as opposed to rural areas (Alt and Lassen 2003). While there is some evidence for that assertion, it is not

\footnotetext{
${ }^{1}$ In Wilson's words: "the degree of public scrutiny of government is not the same at the state as the city level. Big cities have big newspapers, big civic associations, and big blocs of newspaper-reading, civic-minded voters. State capitals, by contrast, are usually located outside the major metropolitan centers of the state in smaller cities with small-city newspapers, few (and weak) civic associations, and relatively few attentive citizens with high and vocal standards of public morality." (p. 596)
} 
overwhelming or particularly robust either (Glaeser and Saks 2006). Needless to say, these are not at all tests of the idea that the isolation of the capital city is related to corruption.

We also relate to the literature on media and accountability, particularly in the US, recent examples of which include Snyder and Stromberg (2010), and Lim, Snyder, and Stromberg (2010). Our evidence is very much consistent with their finding that a disconnect between media markets and political jurisdictions is related to lower media accountability. Most directly, our paper is related to work that has exploited the intersection between urban economics and economic geography, on one side, and political economy - such as Ades and Glaeser (1995), Davis and Henderson (2003), Campante and Do (2010), Galliani and Kim (2011), and Campante, Do, and Guimaraes (2012). A recent literature in political science has also dealt with the political implications of spatial distributions, as surveyed for instance by Rodden (2010) - although without much focus on the idea that some places (e.g. capital cities) are distinctive. We believe this is a very fruitful connection, which should be explored further.

The paper is organized as follows: Section 2 establishes the stylized fact linking isolated capitals and corruption; Section 3 discusses causality; Sections 4-6 discuss the direct links between the spatial distribution of population and accountability, capture, and public good provision (respectively); Section 7 concludes.

\section{A Stylized Fact: Isolated Capital Cities Are Associated with Higher Levels of Corruption}

\subsection{Data: Corruption and Isolation of the Capital}

In order to proceed with our investigation, we obviously need measures of corruption across US states, and of the degree of isolation of their capital cities. We will now discuss in order our preferred measures for these two concepts. Other variables we use will be described later, as they are introduced, and all variables and sources are described in detail in the Online Data Appendix.

\subsubsection{Corruption}

The starting point for any investigation of corruption in the context of US states is the oft-used number of federal convictions for corruption-related crime (relative to the size of the population). (A detailed description of this measure can be found in Glaeser and Saks (2006).) These refer to cases prosecuted by US Attorneys all over the country against public officials and others involved in public corruption, as surveyed and compiled by the Public Integrity Section (PIS) at the US Department of Justice in their "Report to Congress." 2 Federal authorities can claim jurisdiction, for instance, over corruptionrelated crime that "affects interstate commerce," or in entities that receive more than $\$ 10,000$ in federal funds - which yields them a lot of leeway in pursuing cases related to state and local governments.

\footnotetext{
${ }^{2}$ A relatively small subset of these cases are directly prosecuted by the DOJ, typically when there is a recusal from a US District Attorney because of the existence of appearance of conflicts of interest.
} 
These cases usually emerge as a result of an investigation by other agencies, such as the FBI or the IRS, and are eventually referred to the local federal District Attorney (DA). The resulting measure has the substantial advantage of being relatively objective, and focusing on federal convictions alleviates concerns over the differences in resources and political bias that might affect the variation across states. Still, there obviously is variation related to the functioning of local DA offices and federal agencies, introducing measurement error in the variable (Alt and Lassen 2011, Gordon 2009).

The logic of the accountability and capture hypotheses, as we have described in relation to isolated capital cities, pertain most directly to state governments. As such, we would ideally want to measure corruption at that level. The standard measure of federal convictions aggregates state-, federal-, and locallevel officials, plus "others involved," but an alternative approach is to limit consideration to convictions of state-level officials. These are not discriminated on a state-by-state basis in the PIS Report, but some of the information can be recovered from the Transactional Records Access Clearinghouse (TRACfed) at Syracuse University. ${ }^{3}$

In practice, as every conceivable measure will necessarily be a more or less imperfect proxy, the question is what are the pros and cons of each specific approach. The aggregate measure inevitably adds noise - in that events that are essentially unrelated to our logic end up being captured - relative to the measure restricted to state officials. However, it also adds much relevant information. This is first of all because state officials are only a fraction of those who are implicated in corruption at the level of state politics. ${ }^{4}$ Because of that, looking only at the convictions of state officials would systematically and substantially underestimate the extent of state-level corruption.

In addition, the restricted measure is very noisy in its own right. First of all, since there are relatively few state-level officials compared to other levels of government, the share of state officials in aggregate corruption convictions is relatively small - typically about $10 \%$ overall, as compiled in the PIS Report. Second, the TRACfed data do not add up to the total of convictions reported in that Report, with an average number of $30 \%$ left unaccounted for. ${ }^{5}$ The resulting numbers are thus quite small, and correspondingly noisy.

We thus choose to focus on the standard measure as our benchmark. Because it is also very noisy in terms of its year-on-year fluctuations, we focus attention on the average number of convictions, for

\footnotetext{
${ }^{3}$ Another possibility in terms of disentangling state-level corruption would be to look specifically at US Attorney districts that include state capitals. In practice, there is no necessary connection in that regard. For instance, the cases that resulted in the convictions of former Illinois governors George Ryan and Rod Blagojevich were both prosecuted by the Northern District of Illinois, headquartered in Chicago, whereas the state capital Springfield falls under the jurisdiction of the Central District. More generally, our data show no correlation between the number of convictions - aggregate or restricted - and an indicator of whether there is a US Attorney office in the state capital.

${ }^{4}$ As an illustration, consider the case involving former Alabama governor Don Siegelman, who was convicted of corruption charges in 2006. As can be gleaned from the 2006 PIS Report, four people were convicted in addition to the governor, in relation to the same episode, and none of them were state officials.

${ }^{5} \mathrm{~A}$ simple year-by-year comparison between totals in the two sources is not feasible, as the PIS Report refers to calendar years whereas the TRACfed data refers to fiscal years. In any case, the average number of convictions per state-year in the overall measure is about 14, whereas the number for the restricted measure constructed from TRACfed is just under one.
} 
the period 1976-2002. We use this sample of years to keep comparability with the existing literature (e.g. Glaeser and Saks 2006, Alt and Lassen 2008). In any case, we have also looked at more recent updates (up to 2007), and the results are not affected - not surprising, since the correlation between the 1998-2007 average and the standard sample is in excess of 0.80. Averaging over a number of years also helps us deal with political bias at the federal level, as the partisan match between states and federal government - a source of bias identified by the literature (Gordon 2009) - would vary considerably over time.

We will also use the restricted measure, however, in order to check robustness. We have compiled yearly data for each individual state and (fiscal) year between 1986 and 2011, and averaged them over the entire available period, again to deal with the yearly fluctuations that are even noisier in light of the smaller number of convictions. We also normalize the data, using the number of state government employees (as of 1980). As it turns out, its correlation with the standard, unrestricted measure is substantial (just under 0.60).

Finally, for the sake of additional robustness, we will also look at an altogether different approach to measuring corruption. Following Saiz and Simonsohn (2011), we build a measure from an online search (performed in 2009) for the term "corruption" close to the name of each state, using the Exalead search tool. Saiz and Simonsohn (2011) argue that this measure performs well in that it is able to reproduce the standard stylized facts found by the literature on corruption, both at the state and country levels. In our sample, it has a correlation of 0.25 with the standard measure of convictions, which is significant at the $10 \%$ level.

One important limitation shared by these measures is that, to one degree or another, they capture not only what we want them to, namely corruption, but also accountability. The activity of prosecutors and law enforcement is behind the number of convictions, and that of watchdogs, in the media and elsewhere, may also be reflected in a higher number of search hits for corruption. While this is certainly a source of measurement error, we will argue that our results are likely to be underestimated as a result: the direct evidence we will present linking lower accountability to the isolation of capital cities suggests that corruption in states with isolated capitals should be relatively underestimated by our measures, and this would work against the basic stylized fact we find.

\subsubsection{Isolation of the Capital}

When it comes to the isolation of capital cities, what we need is an (inverse) measure of the concentration of state population around the capital. For this, standard measures such as the share of population living in the capital are rather unsatisfactory and coarse, as they rely on arbitrary definitions of what counts as the capital city and discard all the information on the spatial distribution outside of that arbitrarily delimited city. Other measures, such as urbanization or population density, actually capture different concepts, related but clearly distinct from the role of the capital city. We choose instead to make use of 
the axiomatically grounded family of measures that was recently proposed in Campante and Do (2010) the Centered Index of Spatial Concentration (CISC) - which enables a much better look at the concept of interest. Since this is a relatively novel concept, it is worth spending some time describing the measure we will use, as well as its properties.

Campante and Do (2010) show that a very simple and easily interpretable measure of isolation has a number of desirable properties (and uniquely so): the average log distance of the state's population to the capital city - which for shorthand we will describe as AvgLogDistance. ${ }^{6}$ To fix ideas, consider an intuitive measure of isolation of a state's capital, namely the distance between the capital and that state's largest city. AvgLogDistance takes this intuition and applies it in a more comprehensive and systematic fashion. First, instead of looking at the largest city only, it takes into account the entire state: say, instead of looking at the distance between Austin (the capital of Texas) and Houston (its largest city), it takes into account the existence of Dallas-Fort Worth-Arlington, San Antonio, and every other place in the state. ${ }^{7}$ Second, it does so by weighing each place according to its population, so that Houston gets a bigger weight than San Antonio, Dallas, and so forth. It can be shown that this averaging uniquely guarantees key desirable properties. ${ }^{8}$ Finally, the $\log$ transformation can be shown to be the only way to obtain a property of unbiasedness with respect to approximations that have to be performed in computing the measure with actual data. ${ }^{9}$

It is not clear whether a given distance means the same thing in states that are geographically small or large: 100 miles could be seen as a long distance in New Jersey, but not so much in California. Fortunately, since the measure's properties are ordinal rather than cardinal, we can take an agnostic position on that question and experiment with different normalizations. Specifically, we can set the measure so that zero represents a situation of minimum isolation, in which all individuals live arbitrarily close to the point

\footnotetext{
${ }^{6}$ This measure corresponds to what Campante and Do (2010) call the "Gravity-based" CISC (G-CISC). More formally, let $\Omega \subset \mathbb{R}^{2}$ be a convex set that can contain (the representation of) all states, $p_{x}$ denote the distribution of individuals in a given state, defined over $\Omega$, and $z_{\phi x}$ be the distance between a point $x \in \Omega$ and the state capital, which we fix at a point $\phi \in \Omega$. We then have: $G C I S C=\int_{\Omega}\left(1-\alpha \log z_{\phi x}\right) d p_{x}$, where $\alpha>0$ is a normalization parameter to be adjusted so that the measure is contained between 0 and 1 . A description of the index as we actually compute it in practice, given the data we have, can be found in the Online Data Appendix.

${ }^{7}$ The importance of this comprehensiveness is highlighted in this example: Houston is the largest city in Texas, but Dallas-Fort Worth-Arlington is the largest metro area. Any choice of a single "largest" place would be necessarily arbitrary, and needlessly discard information.

${ }^{8}$ Campante and Do (2010) show that averaging (over the distribution of population) iso-elastic transformations of distance to the capital uniquely guarantees the following properties: First, that if a subset of a population becomes more concentrated around the capital, so does the overall distribution (subgroup consistency); second, that moving people closer to the capital implies a more concentrated distribution (monotonicity); and third, that the measure is independent of the units in which distance is measured (rank invariance). In addition, it also satisfies a property of convexity that seems reasonable in our context, namely that a given movement of a person towards the capital has a greater impact on concentration if it happens close to the capital.

${ }^{9}$ Specifically, we compute the levels of concentration of state population around the capital city by using county-level information on population, from the US Census. We thus have to attribute the location of each county's population to the geographical position of the centroid of the county. (While finer geographical subdivisions such as Census tract and block are available - and we do compute concentration using these subdivisions as the unit of observation - the focus on counties enables us to compute the measures for the years before the population data became consistently available at those more detailed levels for the entire US, in 1980.) The G-CISC is uniquely unbiased to that type of measurement error, in that (uniformly) "random" deviations do not change the rankings of distributions as measured by it: technically, it is invariant under mean-preserving spreads of the distribution around points other than the capital.
} 
designated as the center of the capital, while one represents a situation where the capital is maximally isolated, with all individuals living as far from it as possible in the context of interest. We will thus

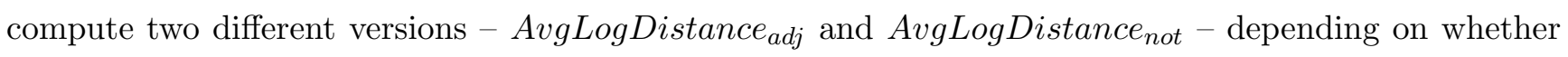
the definition of "possible" adjusts for the geographical size of the state or leaves it unadjusted.

We are able to compute the measures for all Census years between 1920 (when detailed county data first becomes available) and 2000, for 48 states - Alaska and Hawaii are left out as the data for them do not go as far back in time. What does the ranking of states look like in terms of the isolation of their capital cities? Table A1, in the Appendix, provides the answer, as of 2000, for the two different versions of AvgLogDistance. Both measures are sensible in that the rankings are clearly related to whether the capital is the largest city or not. The two measures differ in that the ranking by AvgLogDistance adj does not display much systematic distinction between geographically large and small states. In contrast, the

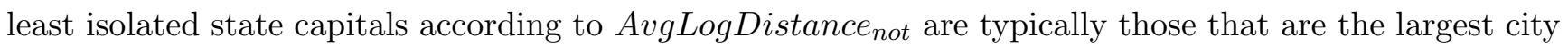
of a geographically small state, whereas the most isolated are in the large states and, within that subset, those which are not their state's largest city. Because of that, we will control for the size and shape of

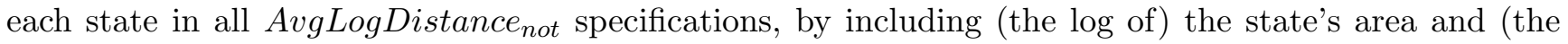
$\log$ of) the maximum distance from county centroids to state capital (i.e. the measure that benchmarks AvgLogDistance $\left.{ }_{a d j}\right)$.

As it turns out, the autocorrelation in both AvgLogDistance not $_{\text {and }}$ AvgLogDistance adj $_{\text {is very high }}$ (see Table A2). Nevertheless, there is nontrivial variation over time. First of all, while the capitals of most states unsurprisingly became less isolated, some became substantially more so - such as Nevada, California or Florida. These were states in which the capital is far from the largest cities, and where the largest cities grew substantially over the 20th century. Second, the variation can be quantitatively important: between 1920 and 2000, Carson City, Nevada became more isolated (in terms of AvgLogDistance ${ }_{n o t}$ ) by roughly one full standard deviation of the 2000 distribution across states. This is roughly the difference between the isolation of Boston, Massachusetts versus that of Trenton, New Jersey.

Because of this nontrivial variation, and because it seems likely that the effects of changes in the distribution of population are likely to be felt over a relatively long period of time, our main specifications will use as independent variables average measures of concentration over time. We will use different averages depending on the relevant period of analysis but, quite importantly, our results are essentially unaltered if we use time-specific measures instead. That said, we will for the most part leave aside the time variation in our estimation, because the fluctuations over time in the corruption variable and the very high autocorrelation in the AvgLogDistance measures make it very noisy, and render its use unwarranted. 


\subsection{Baseline Results}

The raw correlation in Figure 1 obviously does not provide a full picture of the link between corruption and the isolation of capital cities. More systematic documentation can be seen in Table 1, as we control for many other factors that also affect observed levels of corruption. Column (1) displays the correlation

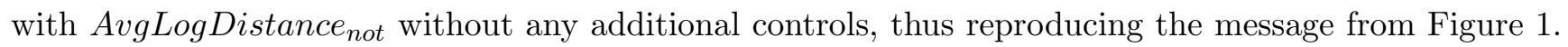
(Just as in that figure, isolation here is measured as an average of the measures calculated up to 1970, i.e. before the time period for which corruption is measured.) Column (2) introduces a basic set of controls, namely (log) income per capita and education, plus (log) population size (to make sure that we are capturing the effect of concentration) and (log) area and (log) maximum distance (as previously mentioned, to control for geographical size, which is not built into AvgLogDistance not $_{\text {). The coefficient }}$ of interest is highly significant, and its size is actually much increased (due to the inclusion of the geographical size controls). Column (3) adds controls other correlates of corruption that are established in the literature, essentially reproducing the basic specification in Glaeser and Saks (2006): the size of government (share of total employment) and urbanization (share of urban population), plus regional dummies. ${ }^{10}$ This does not detract from the size or significance of the positive coefficient on isolation. We adopt it as our preferred specification, as it controls for a number of correlates while keeping a relative parsimony that is called for by the limited sample size. ${ }^{11}$

\section{[TABLE 1 HERE]}

The strength of the isolation variable is further highlighted in Column (4), which adds yet another set of controls often related to corruption- measures of ethnic fractionalization (index of racial dissimilarity), quality of government regulation (Regulation index), and reliance on natural resources (share of value added in mining in the gross state product). The size of the coefficient is slightly reduced, but it is still statistically significant at the $1 \%$ level, quite remarkably in light of the small sample size. The same pattern is also present for our other measure of concentration, AvgLogDistance ${ }_{a d j}$, as shown by Columns (5)-(8) reproducing the four specifications. ${ }^{12}$

We thus see a strong, systematic correlation: states with more isolated capitals are indeed found to display higher levels of corruption. Besides its statistical significance, the effect is also meaningful quantitatively. The average for AvgLogDistance ${ }_{n o t}$ in our sample, for the mean up until 1970, is at

\footnotetext{
${ }^{10}$ Our results are also unaltered if we control for a measure of party competition - often found to be an important correlate of state-level corruption (Meier and Holbrook 1992). We use the so-called "folded" Ranney index, computed for different sub-periods from 1970 through 1999 by King (1989), Holbrook and Van Dunk (1993) and Shufeldt and Flavin (2011), and control for them separately and averaged. The same is true if we control for the share of taxes relative to state expenditures, as the breakdown of state revenues has been suggested to affect corruption (Fisman and Gatti 2002). Both of these sets of results are available upon request.

${ }^{11}$ As evidenced by Figure 1, the results are not sensitive to outliers: they are still present when we run the regressions excluding one Census region at a time.

${ }^{12}$ We do not include controls for geographical size, since this is built into the measure of concentration. The results are not sensitive to that choice.
} 
around 0.69 (roughly the value for Nebraska or South Carolina), with a standard deviation around 0.09. With the coefficient of our preferred specification (1.03), this means that if a state capital becomes more isolated by one standard deviation, the corresponding increase in corruption (0.10) is around threequarters of a standard deviation of the corruption sample. A similar calculation for AvgLogDistance ${ }_{a d j}$, which has a lower standard deviation, would yield a shift of about 0.45 standard deviation. For the sake of comparison, Glaeser and Saks (2006) find in their sample an effect of about half of a standard deviation of a corresponding one-standard-deviation increase in education, a variable that has been consistently found to be (negatively) correlated with corruption (Alt and Lassen 2003, Glaeser and Saks 2006).

\subsection{Robustness: Different Measures of Corruption and Concentration, Placebo Re- gressions}

Let us now consider the robustness of our results, beyond the number of controls considered in Table 1. First, we can probe further into our stylized fact by considering alternative measures of corruption and concentration. This will not only help us check for robustness, but also shed light on the nature of the link between those variables.

We first consider alternative measures of corruption as our LHS variable, starting with the measure of corruption convictions restricted to state officials. Columns (1) and (2) of Table 2 present the results for AvgLogDistance not $_{\text {and AvgLogDistance }}$ adj, respectively, reproducing the main specification from our baseline results (Columns (3) and (7) in Table 1). We run weighted regressions, using the yearly standard deviations of the measures of convictions for each state over the sample period of 1986-2011, in order to adjust for the fact that the small number of convictions entails noise in the yearly measures; however, the results are essentially the same if we run unweighted regressions instead. They very much confirm the message from Table 1. Even quantitatively, the results are fairly similar, and especially so when we take into account that this is a noisier measure: an exercise along the lines of what we have done for the baseline results would yield an effect of just over 0.55 standard deviation. In other words, isolated capital cities are still associated with higher measured corruption when we restrict that measure to the narrow subset of state officials.

\section{[TABLE 2 HERE]}

We then look at the alternative measure of corruption proposed by Saiz and Simonsohn (2011), using the Exalead search tool. (Note that here, since the measure of corruption is computed over a more recent period, we use the average of the measures of concentration up to 2000, and use the demographic control variables as of 2000 as well.) Columns (3) and (4) again mimic the main baseline specifications, and again find very similar results. The estimated quantitative effect is now of about 0.7 standard deviation, once again very close to the baseline. ${ }^{13}$

\footnotetext{
${ }^{13}$ We also experimented with the measure of corruption perceptions introduced by Boylan and Long (2002) and used by
} 
Another dimension of robustness is to check for alternative measures of concentration relative to the capital city. A simple alternative is to consider the average distance, without the log transformation. This yields a measure, AvgDistance, that does not display the same unbiasedness property as AvgLogDistance, but it is reassuring that the results are still present with both versions, AvgDistance not $_{\text {. }}$ and AvgDistance $a d j$, as shown in Columns (5) and (6) - not surprisingly when we consider that the raw correlation between AvgLogDistance and AvgDistance measures is around 0.8.

For the sake of completeness, we can also consider the coarser measures of concentration of population relative to the capital. We look at the share of population living in the state capital (as of 2010), and a dummy variable for whether the capital is the largest city in the state. Both of these variables are negatively correlated with AvgLogDistance not $_{\text {and }}$ AvgLogDistance ${ }_{a d j}$, as one would expect. The raw pairwise correlation hovers around -0.3 in all cases, significant at the $5 \%$ level. We use these measures in regression specifications otherwise identical to those in Columns (1) and (2), using the "Exalead" measure in light of the time period for which we have the population data at the city level. As it turns out, we see a statistically significant negative coefficient in Columns (7) and (8), consistent with the baseline results. The quantitative implications, however, suggest in both cases a decrease in corruption of about one third of a standard deviation - for a one-standard-deviation increase in the share of the population in the capital and for a change from the capital not being to its being the largest city, respectively. This smaller effect is consistent with a substantial measurement error being introduced by the use of these coarse measures.

A second check is to probe the results with a few "placebo" regressions. In that regard, we can start by asking whether there is indeed something special about the capital city, as opposed to other features of the spatial distribution of population. For that we consider a "placebo" measure that does not place the capital city per se in any special role: the isolation of the largest city in each state. Since the latter is sometimes - in 17 out of 50 states - also the capital city, one might wonder whether the measure of isolation of the capital could be in fact proxying for that. Columns (1)-(4) in Table 3 dispel that notion: the isolation of the largest city has no independent effect and, most crucially, its inclusion does not affect the significance or size of the coefficient on the isolation of the capital.

\section{[TABLE 3 HERE]}

That the isolation of the largest city does not seem to have an independent effect on corruption is also interesting in its own right. In fact, it provides additional indirect evidence against the capture view linking corruption to the spatial distribution of population and economic activity. From this view one might have expected that the spatial concentration of economic power, as proxied by the concentration

Alt and Lassen (2003), based on a question posed to reporters covering the State House and available for 47 states. The regression results have high standard errors, but quantitatively the estimates are again very similar to our baseline: the

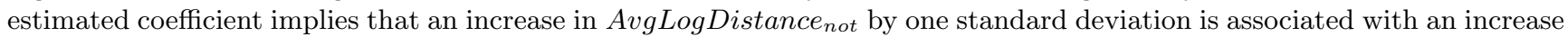
in the measure of corruption perception of about 0.8 standard deviation. (These results are also available upon request.) 
of population around the main economic center, could be associated with a higher risk of capture, even leaving aside the location of the capital city. The evidence suggests that this does not seem to be the case.

Another kind of "placebo" test is to check for different outcome variables. If the stylized fact is indeed saying something specific about corruption at the state level, one would expect that there would be no particular connection between the isolation of the capital city and the prevalence of (or federal prosecutorial efforts in pursuing) other types of crime that are presumably unrelated to state politics. We check that, in Columns (5)-(8), using a measure of criminal cases related to drug offenses that are brought by prosecutors to federal courts in each state (as of 2011). We choose drug offenses because they are by far the most numerous among the cases brought before federal courts. Columns (5)-(6) show that there seems to be no connection whatsoever between the number of drug cases and the isolation of the capital. To check that this is not driven by outliers, we then drop the states on the Mexico border - which tend to have a disproportionate number of drug-related cases (especially Arizona and New Mexico). In Columns (7)-(8) we see that the same pattern holds in that case.

These results also help alleviate the concern that the results might be driven by differences in the ability, zeal, or resources available to federal prosecutors - at least to the extent that these differences apply across different types of cases. It could still be the case, of course, that differences that are specific to corruption cases are playing a role, but that no such differences appear to be driving spurious results in other domains is reassuring nonetheless.

In sum, the relationship between the concentration of population around the capital city and corruption in US states seems robust to different measures of both concepts. The evidence also suggests that there is something particular about the capital city and about corruption - and in fact in a way that seems to be again consistent with the accountability view, and in dissonance with the capture view that we have discussed.

\section{$3 \quad$ Is There Evidence of Causality?}

\subsection{Identification Strategy}

Can we go beyond the correlations uncovered in the previous section? To understand the issues more clearly, consider a set $\Omega \subset \mathbb{R}^{2}$ containing the maps of all states, and denote the location chosen as the capital city by a point $\phi \in \Omega$. Now let $X \in \mathbb{R}$ be our measure of the isolation of the capital city. This is a function of $\phi$, of course, and also of the spatial distribution of population over the state, denoted by $\mathbf{F}$ defined over $\Omega$. The latter is in turn a function of the spatial distribution of state characteristics that condition individual decisions on where to locate, denoted by $\mathbf{G}$ (also defined over $\Omega$ ) - for instance, people will be more likely to live in a given part of the state if that's where there is a navigable river, or canal, or a gold mine, or better road infrastructure, and so on. It is also a function of the location 
of the capital city, since this will affect the propensity of individuals to live in that specific location and elsewhere. In sum, and with a slight abuse of notation, we have $X(\phi, \mathbf{F}(\mathbf{G}, \phi))$. Let $Y$ be our outcome variable of interest, corruption, then we want to estimate the parameter $\beta$ in a model such as:

$$
Y=\beta X(\phi, \mathbf{F}(\mathbf{G}, \phi))+W \Gamma+u,
$$

where $W$ stands for the observable determinants of corruption, in addition to the isolation of the capital city, and the error term is $u$.

The endogeneity problem, of course, is that it could well be the case that $X$ and $u$ are correlated, because $\phi$ may be correlated with $u$. (1) makes clear that this is because of two reasons: both the institutional choice of capital and its impact on individual decisions on location could be correlated with corruption. For instance, corruption and the location of the capital city could be jointly determined - say, with relatively corrupt states choosing to isolate their capital cities. Alternatively, it could be the case that corruption affects the population flows that determine how isolated the capital city will ultimately be - perhaps corruption would push economic activity and population away from the capital. As a result, we have two confounding factors posing identification challenges.

To deal with them, in the absence of something like a natural experiment on the location of capital cities, we need sources of exogenous variation in the isolation of the capital. One possible source along these lines can come from a specific point of interest: each state's centroid. Specifically, the centroid is the average coordinate of the state: a point $\psi \in \Omega$ such that $\psi=\frac{\int_{\Omega} x d x}{\int_{\Omega} d x}$. As such, it does not depend on the spatial distribution of a state's population, but only on the state's geographical shape.

The first crucial point is that the centroid is an essentially arbitrary location and should not affect any relevant outcomes in and of itself: in terms of our simple model, $\psi$ should be uncorrelated with $u$. This should be true at least once the territorial limits of each state are set. ${ }^{14}$ Because of that, we will eventually control, in all of our specifications, for the geographical size of the state: we include it in $W$ to guard against the possibility that a correlation between omitted variables and the expansion or rearrangement of state borders might affect the results.

The second crucial point is that there is a connection between the location of the centroid and the location of the capital city, which is obviously a necessary condition for the variation in the former to generate meaningful variation in the latter. As it turns out, the history of the designation of state (and federal) capitals in the US strongly suggests exactly such a link. This is because concerns with equal representation led to strong pressures to locate the capital in a relatively central position, particularly as state capital cities were typically chosen at a time when transportation and communication costs were substantial (Zagarri 1987, Shelley 1996). ${ }^{15}$ A quick inspection of a map of the US displaying all state

\footnotetext{
${ }^{14}$ State borders have been generally stable after establishment. For a history of those borders, see Stein (2008).

${ }^{15}$ For instance, back in 1789, James Madison argued that, as a matter of equality and political stability, the capital cities of the states, and of the Union, ought to be placed "in that spot which will be least removed from every part of the empire," as opposed to other "eccentric" locations. This was in line with an ancient tradition advocating a centrally located capital
} 
capitals makes it immediately apparent that many of them are actually in relatively central locations, consistent with what the history would lead us to expect.

The key question is then how to turn this source of exogenous variation into an instrumental variable that we could use to estimate the causal effect of $X$ on $Y$. The natural candidate is the isolation of the centroid in terms of population, CentroidAvgLogDistance ${ }_{n o t} \cdot{ }^{16}$ We can check that in practice, as one would expect from the previous discussion, there does seem to be a positive correlation between the isolation of the capital and the isolation of the centroid, as illustrated by Figure 2.

\section{[FIGURE 2 HERE]}

This proposed instrument can be written, in terms of our simple model, as $Z_{1}(\psi, \mathbf{F}(\mathbf{G}, \phi))$. This means that the variable indeed purges the direct influence of the endogenous location of the capital, $\psi$, as it does not depend directly on the latter. However, it is still a function of the distribution of population, and could thus still be contaminated by the influence of $\phi$ over the distribution of population across the state.

In order to deal directly with that second potential source of exogeneity, we will combine the role of the centroid with a second source of exogenous variation affecting the spatial distribution of population: the spatial distribution of economic resources. More specifically, we use data on the spatial distribution of land suitability for cultivation, aggregating data on soil and climate properties. ${ }^{17}$ These data let us compute how "isolated" the centroid is, not with respect to population, but rather in relation to cultivation-suitable land: an isolated centroid would correspond to a situation in which the most suitable land in the state is relatively far from the centroid.

The idea is that the spatial distribution of population, particularly in pre-industrial days, would be affected by land suitability, as people would be more likely to settle in places well-suited for agriculture. The persistence in that spatial distribution would in turn suggest that this influence should persist as well. We would thus expect that, in case the centroid is isolated with respect to suitable land, it would also tend to be isolated when it comes to population. What is more, so would be the capital city, to the extent that it tends to be located close to the centroid. Crucially, it is eminently plausible that the exclusion restriction is satisfied: spatial patterns in terms of climate and soil, relative to the state's centroid, would neither be meaningfully affected by current population patterns that could be correlated with corruption, nor likely to affect corruption through any means other than their impact on the distribution of population relative to the capital.

city, dating all the way back to Aristotle's description, in his Politics, of the ideal location for the seat of government as a "common centre, linked to the sea as well as land, and equally linked to the whole of the territory." (Zagarri, 1987, p. 27)

${ }^{16}$ Results using CentroidAvgLogDistance ${ }_{a d j}$ are similar, and available upon request.

${ }^{17}$ See the description in Ramankutty et al (2002). Land suitability is measured as the probability that a given area will be cultivated, calculated as a function of climate and soil properties. Climate properties included are annual sum of days with mean temperature above 5 degrees Celsius and the ratio of actual to potential evapotranspiration; soil properties are soil carbon density and soil acidity $(\mathrm{pH})$. 
We thus compute SuitCentroidAvgLogDistance ${ }_{n o t}$ for the 48 states in the continental US, and use it as an alternative instrumental variable. In terms of our model, we can denote it as $Z_{2}(\psi, \mathbf{G})$, which makes clear that this variable has the advantage of taking care of both of our sources of endogeneity: it is unlikely that the distribution of land suitability around the centroid is correlated with omitted determinants of corruption. Its main drawback is that, quite naturally, it has a more tenuous correlation with our variable of interest, namely the isolation of the capital.

It is instructive to look at the correlation between $Z_{1}$ and $Z_{2}$ and a number of "predetermined" variables - namely variables that cannot be affected by contemporaneous levels of corruption or by its current covariates. We select variables that are either geographical in nature or are measured far back in the past, as contained in the 1878 US Statistical Abstract. One would expect that, if the isolation of the centroid in terms of population and land suitability were to vary systematically across state characteristics that might correlate with current levels of corruption, this would be picked up by a few of those predetermined variables.

Columns (1)-(2) in Table 4 display the raw pairwise correlations. We can see that both variables seem correlated with a number of geographical variables. As it turns out, these correlations are misleading, because of that which exists, by construction, between a state's AvgLogDistance ${ }_{n o t}$ and its geographical size. Columns (3)-(4) thus control for that by conditioning the pairwise correlations on geographical size. ${ }^{18}$ It then becomes clear that these are essentially uncorrelated with the concentration of population or land suitability around the centroid.

\section{[TABLE 4 HERE]}

In other words, states with population or land suitability highly concentrated around the centroid look ex ante rather similar to those with low concentration. In particular, this is true along a few important dimensions: there seems to be no systematic differences between older and newer states; Second, more and less concentrated states (around the centroid) also look similar with respect to key geographical characteristics, such as the presence of mountains or rivers or the size of borders and coastline; and there seems to be little difference with respect to economic factors such as natural resources or transportation networks. This reassures us that the exclusion restriction is indeed plausibly satisfied for both instruments.

\subsection{Results}

We can now check the two-stage least-squares (2SLS) results in Table 5, starting in Panel A with CentroidAvgLogDistance, the population-based instrument. We start off in Columns (1)-(2) by displaying the first-stage results for the full specification, i.e. with the full set of controls. (The results are similar

\footnotetext{
${ }^{18}$ Specifically, we run a regression of each measure of the concentration of population around the centroid on (log) area and (log) maximum distance, plus regional dummies, and compute the pairwise correlations of the residuals from these regressions with the other predetermined variables.
} 
for the other specifications.) We can see that it is indeed a significant predictor of AvgLogDistance. The F-statistic for the excluded instrument is reasonably high for both AvgLogDistance ${ }_{n o t}$ and AvgLogDistance ${ }_{a d j}$, but relatively close to standard thresholds for weak-instrument-robust inference. ${ }^{19}$ In light of this, in the rest of the table we display the p-values as given by the minimum distance version of the AndersonRubin (AR) test, which is robust to weak instruments. Columns (3)-(8) then reproduce in order, for comparison's sake, the specifications with controls from Table 1.

\section{[TABLE 5 HERE]}

We do see confirmed the significant effect of having an isolated capital on corruption. As it turns out, the point estimates are generally considerably greater, in absolute value, than the corresponding OLS results in Table 1. For instance, in the case of AvgLogDistance ${ }_{n o t}$, our preferred specification corresponds to an effect that is about $70 \%$ larger than previously. This means that the same quantitative exercise we had before - a one standard deviation increase in isolation - would yield an impressive increase in corruption of about 1.25 standard deviation.

Panel B in turn runs the same exercise using our second, land-suitability-based instrumental variable, SuitCentroidAvgLogDistance $_{n o t}$. Unsurprisingly in light of the inherently weaker link between it and the isolation of the capital city, the first stage is weaker. The instrument is nevertheless still a significant predictor of the isolation of the capital at the $5 \%$ level. Columns (3)-(8) show that we also find a generally significant effect of the isolation of the capital city on the measure of corruption. ${ }^{20}$

Quite interestingly, the coefficients are remarkably consistent with those obtained in Panel A, even if estimated a bit less precisely. This suggests that the potential bias stemming from our second source of endogeneity is not very important in practice, and is reassuring in that the evidence for a causal impact of the isolation of the capital city on corruption seems robust to the different sources of endogeneity. This stability of coefficients is also reassuring, of course, in relation with the potential threat of the relative weakness of the land-suitability instrument.

In sum, while we are short of a true natural experiment where state capitals would have been randomly assigned, plausible sources of exogenous variation suggest that behind our stylized fact lies indeed an effect of having an isolated capital city on the prevalence of corruption in a given state.

\footnotetext{
${ }^{19}$ Specifically, the Cragg-Donald Wald F-statistics are 10.34 and 12.52 , respectively, for AvgLogDistance ${ }_{\text {not }}$ and AvgLogDistance adj. This lies between the $10 \%$ and $15 \%$ thresholds of the Stock-Yogo weak instrument maximal IV size critical values (Stock and Yogo 2005), meaning that the instrument would be considered weak if we were to limit the size of the conventional IV Wald test to at most 0.1 above its nominal value. We take this to mean that the instrument is not obviously weak, but in any case we choose to present the robust inference as well.

${ }^{20}$ While from Figure 2 it may appear that states such as Utah, Colorado, Connecticut, and Maryland might be driving results, all of our findings are robust to the exclusion of these states.
} 


\section{Accountability and the Spatial Distribution of Population}

This connection between isolated capital cities and higher levels of corruption is evidently consistent with the hypothesis that politicians in isolated state capitals face lower levels of accountability. We will now look for direct evidence that this is actually the case: is the accountability of state-level officials affected by the spatial distribution of population?

We can take a first look at this possibility by inquiring about their compensation patterns. If politicians are less accountable in states with isolated capitals, one might expect that they would also obtain higher rents through higher official compensation. We check for that using data on the annual compensation of state governors, from 2008, as compiled by the Alaska Department of Administration. We focus on the compensation of governors because of ease of comparability. State legislatures, for instance, vary enormously in terms of basic characteristics such as the frequency with which they convene, so that it becomes very hard to compare compensation across different states.

Table 6 displays the results of this simple exercise. The first four columns essentially reproduce, again for comparability, the basic specifications studied for corruption (as in Columns (2)-(3) and (6)-(7) of Table 1), only now with (the log of) governor salaries substituted as the dependent variable. We see a positive, statistically significant coefficient of interest: the governors of states with more isolated capital cities receive greater compensation (as a share of per capita income). In fact, using the coefficient from our preferred specification (Column (2)), it follows that a one standard deviation increase in the isolation of the capital increases compensation by just under $85 \%$ of a standard deviation. Columns (5)-(8) in turn display the 2SLS specifications, using the isolation of the centroid with respect to population and suitable land as our instruments. They suggest evidence of a causal impact of the isolation of the capital on compensation, consistent with lower accountability.

\section{[TABLE 6 HERE]}

Note in particular that all of these results hold while we control, in all specifications, for the ratio between median housing list prices (per square foot) in the capital and in the state as a whole (obtained for July 2012 from the real estate website zillow.com). This alleviates the concern that the higher compensation is simply necessary to convince state officials to live and/or work in a more isolated place, as the variable captures at least partly how desirable it is to live in the state capital. (In fact, the ratio of house prices is always far from being a significant predictor of salaries.)

In other words, we have prima facie reason to suspect that accountability is indeed weaker in states with isolated capital cities. Still, this begs the question of what are the accountability mechanisms that may be affected by the spatial distribution of the population around the capital city. We will now pursue a systematic look at two possible versions of this hypothesis: the role of the media and the role of of the electoral process. 


\subsection{The Role of the Media}

To the extent that media outlets are at least partly trying to provide content that interests their audience (e.g. Mullainathan and Shleifer 2005, Gentzkow and Shapiro 2010), and to the extent that media consumers are at least somewhat more interested (ceteris paribus) in what happens close to where they live, it would be reasonable to expect that an outlet's coverage would focus on things that take place where its audience is concentrated. If so, outlets whose audience is more concentrated around the capital city would tend to give more extensive coverage of state politics. As a result, one would conclude that in states where the population is more concentrated around the capital there would be more intense media coverage of state politics, and therefore greater accountability, with better informed citizens.

This is an evidently plausible story, but it actually weaves together hypotheses about the behavior of media outlets and of individuals. We will look at these two different levels, in order.

\subsubsection{Newspaper-Level Evidence}

We start off by looking at whether media coverage of state politics reacts to the spatial distribution of media audiences. We will focus on newspapers, since it is widely understood that they provide far greater coverage of state politics in the US than competing media such as TV (e.g. Vinson 2003, Druckmann 2005), and since it is also the case that their audiences tend to be more geographically concentrated than those of TV. Newspapers also happen to have more easily searchable content, which will come in handy for our investigation.

A Motivating Example To motivate this nexus, let us consider a couple of corruption episodes bringing together our aforementioned comparison between New York and Massachusetts. Both states have witnessed recent corruption scandals that led to the indictment and eventual conviction of two very prominent state legislators: former Senate Majority leader Joseph Bruno, in New York, and former House Speaker Salvatore DiMasi, in Massachusetts. We can learn about the scope of media accountability in both states by looking at these scandals and how they were covered by the New York City and Boston press.

In 2007, Bruno had been serving as the Majority leader for thirteen years. As such, he was one of the "three men in a room," along with the governor and the Assembly speaker, who are reputed to run New York state politics (Lachman and Polner 2006) - a popular description that in and of itself indicates a system without much accountability. In that year, political scandal forced him to resign from a consulting job with a firm involved in managing funds for politically powerful unions - a job that led to his being investigated by the FBI. (New York legislators are legally allowed to have other jobs besides their legislative office.) In 2008, as a result of the fallout from that investigation, he chose not to run for reelection and eventually resigned from his seat. In early 2009 he was formally indicted on eight counts of corruption, for allegedly using "his powerful position to help entities with business before the state 
that in return paid him $\$ 3.2$ million in private consulting fees." (The Saratogian, 01/24/2009) He was later convicted in late 2009, by the Federal District Court, on two counts of fraud. He was sentenced to two years in prison, although he has remained free during appeal. His case was certainly not unique: one of the Majority leaders that succeeded Bruno was later indicted on six counts of embezzlement and theft, in 2010, and lost his reelection bid in the process.

Around the same time, DiMasi also resigned from his position as Massachusetts House Speaker, in 2009, amidst a massive scandal involving extorsion and receiving kickbacks in return for government contracts. He was eventually indicted in nine corruption charges, and later found guilty of seven of these counts in a federal court, in 2011. He got sentenced to eight years in prison, which he started serving in November 2011. This episode represented the third straight instance of a Massachusetts House Speaker being federally indicted.

In other words, we have two comparable scandals involving prominent politicians in these two neighboring Northeastern states. Both led to high-profile convictions, in scandal-plagued environments. It is interesting, however, to contrast the coverage devoted to these cases by the main newspapers from the respective states' main cities: New York City, located just over 100 miles away from the state capital Albany, and Boston, which happens to be the capital itself. A search for "Joseph Bruno" (or "Joseph L. Bruno") and "corruption" in November 2011 yielded 154 articles in the online archives of the New York Times, 77 in the New York Post, and 91 in the New York Daily News. The same search with "Salvatore DiMasi" (or "Salvatore F. DiMasi"), on the other hand, yielded 238 matches in the Boston Globe and 130 matches in the Boston Herald. The difference is more remarkable if we control for the size of the different newspapers: a "neutral" search (for the word "Monday," following Gentzkow et al. (2005)) reveals, for instance, that the New York Times is about twice the size of the Boston Globe. In sum, Boston newspapers seem to have devoted substantially more coverage to the DiMasi scandal than New York City newspapers did to the Bruno affair - consistent with the idea that their readership might be more interested in what goes on in Beacon Hill (the central Boston neighborhood that is the site of the state government) than the New York papers' is in what takes place in Albany.

Illustrative as an anecdote can be, it obviously cannot establish a pattern on its own. For instance, one might wonder if the journalistic interest of the DiMasi case could be inherently greater, or whether more coverage of corruption scandals is actually the outcome of their occurring more often - although New York is measured as more corrupt than Massachusetts in all of our available measures. In any case, we need a more systematic look at the evidence.

The Evidence We use the newspapers whose content is available and searchable at the website "NewsLibrary.com" - covering nearly four thousand outlets all over the US. In order to proxy for their coverage of state politics, we search in each newspaper for the names of each state's then-current governors - as well as, alternatively, for terms such as "state government," "state budget," or "state elections", 
where "state" refers to the name of each state - between January 1st 2008 and December 31st 2009. (Details of the search are in the Data Appendix.) ${ }^{21}$ Because we want to guard against reverse causality when it comes to corruption - ie, the possibility that there is a lot of media coverage because of the existence of corruption scandals - the idea here is to look for terms that are not necessarily related to this type of episode - though it can certainly be the case (and actually is, for some states) that governors are involved in a few of those. Note also that we only take into account mentions to the state in which each newspaper is based. Finally, we control for newspaper size by running a search for a "neutral" term ("Monday"), as mentioned above.

We then want to check how that coverage of state politics is conditioned by how close each newspaper's audience is to the capital city. For that we look at the circulation data provided by the Audit Bureau of Circulations (ABC), which breaks it down by county, and allocate every reader in a given county as if she lived in that county's centroid. This information on the spatial distribution of each newspaper's total circulation in a given state lets us measure the concentration of its readership around the state capital: we define ReaderConcent as 1 - AvgLogDistance with respect to the capital, with the average now taken with respect to newspaper circulation. The number of newspapers with ABC data available is considerably smaller than what NewsLibrary.com covers, so we end up with a total of 436 newspapers in our sample. Also, we leave aside the circulation of a newspaper outside of its home state, since we are focusing on coverage of home-state politics. For newspapers that have substantial circulation outside their home state, this would tend to overestimate the degree of concentration of their circulation around the home-state capital - a source of measurement error that should be kept in mind when interpreting the results below.

The basic hypothesis to check would be that a newspaper's coverage of state politics is increasing in how concentrated its readership is around the state capital. For this we first run regressions of different measures of state-level political coverage on ReaderConcent - controlling for newspaper size (proxied by the "Monday" search), circulation and state fixed effects. We find coefficients that are generally positive and significant, as we can see in Table $7 .^{22}$ In addition, we would expect the kind of measurement error introduced by out-of-state circulation to lead these estimates to be biased downwards: newspapers with significant out-of-state circulation would likely have an incentive to provide less coverage of home-state politics, and the concentration of their circulation is being overestimated in our calculation.

\section{[TABLE 7 HERE]}

In sum, it seems that newspapers do tend to give state politics greater coverage when their audience is more concentrated around the capital.

\footnotetext{
${ }^{21}$ Similar procedures using NewsLibrary.com have been used, for instance, by Snyder and Stromberg (2010) and Lim, Snyder, and Stromberg (2010).

${ }^{22}$ Note that in this case the presence of state fixed effects makes the normalization of the concentration measure immaterial.
} 
Aggregation We can also look at this question at an aggregate level, as opposed to that of individual newspapers. To get at this angle, we compute an aggregate state-level measure of political coverage as a weighted sum of the newspaper-level measures. We use two alternative sets of weights: the circulation of each newspaper in the state, and that circulation weighted by its geographical concentration as captured by the ReaderConcent variable. The latter would put more weight on circulation closer to the capital, and thus allows for the possibility that the content of newspapers whose audience is more concentrated around the capital city might have a disproportionate effect on the behavior of state politicians. However, because of the measurement error that we have highlighted above, we will think of the first set of weights as our preferred measure. As far as measurement error is concerned, we should also note that the aggregate measure introduces an additional source, due to the fact that the ABC and NewsLibrary.com data do not cover the totality of a state's newspaper industry. There is no particular reason to believe that this measurement error is correlated with the underlying value of the variable we want to measure, so we would in principle expect a possible downward bias emerging from that. For brevity, we will summarize media coverage with the first principal component of the four aforementioned alternative measures, which are all adjusted by newspaper size.

The regression evidence, in Table 8, confirms a correlation at the aggregate level: states with isolated capitals tend to display lower levels of media coverage of state politics. ${ }^{23}$ The effect is considerably stronger for the AvgLogDistance ${ }_{a d j}$ measure, indicating that what matters most for the connection is how isolated the capital city is, not so much in terms of absolute distances, but rather relative to the geographical size of the state. ${ }^{24}$ Similar results obtain when we use our measure of isolation of the state centroid in terms of population as an instrument for the isolation of the capital: we see a significant effect

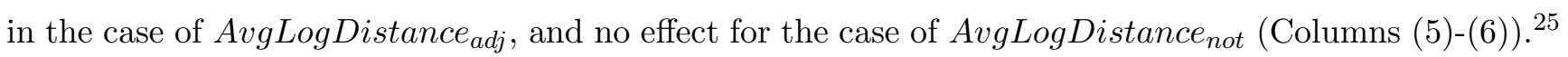
That said, the significance of the results is sensitive to the exclusion of the states of South Dakota and Delaware. These are not outliers in a strict sense - they are not even two standard deviations below the mean or median - but this does add some grains of salt to the interpretation of the aggregate evidence.

\section{[TABLE 8 HERE]}

In sum, there is some evidence that the aggregate level of coverage seems to respond to the overall level of concentration.

\footnotetext{
${ }^{23}$ We include in our set of control variables a dummy for whether the state had an election for governor in one of the years to which our newspaper search refers (2008 and 2009), in order to account for the possibility that coverage of state politics would react to the proximity of elections.

${ }^{24}$ The results are largely the same if we exclude Rhode Island, which turns out to be a positive outlier in the media coverage variable - about five standard deviations greater than the state with the next largest measure. This is because there is one newspaper, the Providence Journal, that far outstrips the circulation of all other RI-based newspapers in the sample, This newspaper had a very large measure of coverage of state politics, and is idiosyncratically driving the state-level measure.

${ }^{25}$ Results are also similar when we use the isolation of the centroid with respect to suitable land as our instrument, which we omit for the sake of brevity.
} 


\subsubsection{Individual-Level Evidence}

The evidence at the newspaper level begs the question of whether individuals indeed display lower levels of interest and information regarding state politics when they are farther away from the state capital. This pattern would match the newspaper-level evidence in two respects: if relatively distant individuals are less interested in state politics, this might help explain why newspapers would provide less coverage; on the other hand, less coverage could well reinforce the pattern of lower interest in and knowledge of what happens in the capital. To the extent that accountability is ultimately provided by citizens, observing that kind of individual-level would be important in shoring up the accountability view.

In order to pursue that angle, we need information on individual interest and knowledge regarding state politics that we could match to each individual's location relative to the capital city. For that we can rely on the American National Election Studies (ANES). In the 1998 pre-election survey, a random sample of 1203 voting-age citizens were interviewed, in the states of California, Georgia, and Illinois - a set that, incidentally, happens to cover a wide range in terms of the isolation of the respective capital cities, as evidenced by Table A1. As usual for the ANES up until 2000, the 1998 survey includes information about the county of each interview, which we use to compute distance (from the county centroid) to the state capital. Most interestingly and uniquely, it includes questions that directly measure knowledge of state politics and interest in news coverage related to state politics.

Specifically, we code a dummy for Knowledge that captures whether the individual respondents are able to provide the correct name of at least one candidate in the upcoming gubernatorial elections. As for interest in news regarding state politics, we code a dummy for Interest that captures whether the respondent reports to care about newspaper articles about the gubernatorial campaign, conditional on her reading newspapers. We condition on the latter in order to focus on the level of interest displayed by potential consumers of print media.

In addition to these two main variables of interest, we also take from this survey two pieces of information. First, we create a dummy variable based on respondents answers on whether they follow public affairs in general. This will let us gauge the level of GeneralInterest in politics, unconstrained to the state level. We will make use of that to run a placebo specification, as we do not expect that general interest in politics would be necessarily affected by one's location relative to the state capital. Second, we use the fact that interviewers were asked to assess the respondents' general level of information about politics and public affairs. We will use this as a control variable, so that our results will look at the effect of distance conditional on the respondents' general level of information, again beyond the confines of state politics.

Table 9 shows the results of probit specifications, with (the log of) distance to the state capital being the main independent variable of interest. For all dependent variables, we first show the specification with county-level controls only, and then include individual-level controls. ${ }^{26}$ In all specifications we cluster

\footnotetext{
${ }^{26}$ The control variables, besides the general level of information, broadly follow Gentzkow (2006), who runs specifications
} 
the standard errors at the county level and include state fixed effects, and marginal effects are reported.

\section{[TABLE 9 HERE]}

Columns (1)-(2) show a robust, statistically significant pattern: individuals who are farther from the state capital are substantially less likely to be informed about state politics. Quantitatively speaking, our preferred specification with all individual- and county-level controls implies a marginal decrease of 8 percentage points from a mean probability of knowing the name at least one candidate for governor around $66 \%$. We can also see a significant correlation between distance and the level of interest in state campaign news within the subset of newspaper readers, at least once we control for individual characteristics. The quantitative implications are also quite substantial, with a marginal effect of about 6 percentage points off a $40 \%$ mean probability of paying attention to campaign news among newspaper readers in the sample. In other words, living farther from the capital substantially decreases the level of interest in state campaigns among individuals with comparable demographics and with a comparable level of information about policy in general. Last but not least, Columns (5)-(6) display the results of our placebo test. They show that the correlation with distance is distinctly absent when it comes to the level of individual interest in government and public affairs in general, just as we expected.

In short, there seems to be a robust connection between the spatial distribution of individuals relative to the capital city and their engagement with state-level politics - a connection that we do not spot when it comes to interest in politics in general. This pattern at the individual level seems to match and presumably reinforce what we have seen at the level of newspapers, as the relative disengagement of audiences farther from the state capital may both discourage newspapers from covering state politics and be fed by that reduced coverage. Put together, these pieces of evidence suggest that where individuals are located matters for media accountability, and in ways that are eminently consistent with the evidence in favor of the accountability view linking isolated capital cities to greater corruption.

\subsection{The Role of Voters}

It is quite possible that other forms of holding state officials accountable could be linked to the spatial distribution of that state's population. Particularly in light of the individual-level evidence we have presented regarding the media, if those who are farther away from the center of power are less engaged with state politics, it could well be the case that this disengagement would also make them less likely to vote. As a result, voter turnout, and hence the degree of accountability provided by the electoral process, could be affected by that spatial distribution. While we are not aware of this hypothesis being tested directly in the context of the US, similar effects have been detected elsewhere (Hearl, Budge, and Pearson 1996, Dandoy 2010), with regions far from capital cities displaying lower turnout.

based on similar ANES data. 
The basic empirical question then is whether it is the case that people who live closer to the state capital city would be more likely to turn out in state-level elections. One alternative to tackle this question would be to look at individual-level survey data on turnout and match it to data on where individuals are located. However, survey data on turnout is notoriously unreliable (e.g. Burden 2000). We thus choose to look at actual turnout data at the county level, once again attributing for simplicity the county's population to its centroid, and computing the distance between each county's centroid and the state capital. We use data from the election cycle between 1997 and 2000, so that we can cover all states and use more comfortably the demographic variables from the 2000 Census.

Table 10 runs the county-level regressions shows a very strong and robust negative effect of distance to the capital on turnout: people who are closer to the capital city are indeed more likely to turn out in state elections. The basic result in Column (1) controls for basic demographics (education, income, and density of voting-age population) and state fixed effects, so that we focus on within-state variation in obtaining our estimates. Column (2) then shows it clearly survives additional demographic controls that may matter for turnout, such as poverty and inequality, ethnic and religious composition, and the age profile of the population.

\section{[TABLE 10 HERE]}

We again check that what we find is indeed related to the special role of the capital city, by including a "placebo" variable such as distance to the state's centroid. If we run the regression without distance to the capital (Column (3)), the "placebo" variable comes out significant, but Column (4) shows very clearly that distance to the capital is what really matters in predicting turnout. Similar results emerge if we use distance to the state largest city instead.

If we follow the logic of the hypothesis linking distance to state capital to turnout, we are led to conjecture that the link would not hold - or at least should be weaker - for presidential elections. After all, there should be less of an asymmetry between how national politics is felt in state capitals relative to other locations in a given state. We can test for that by looking at the different timing of elections in our sample. More specifically, state elections coincided with presidential elections, in our sample, only in the year 2000, and we can check whether the link between distance and turnout would be weaker in those years - where presumably turnout would be more heavily affected by forces unrelated to state politics. Sure enough, if we run the regression for the year 2000 only, Column (5) shows that we obtain a coefficient that is less than one-half the size of the effect for the whole sample, and short of statistical significance at the $10 \%$ level. In contrast, if we run the same regression restricting the sample to the "off"-years of 1997 and 1999 - where no federal election took place - we get a coefficient (Column (6)) that is about five times as large as the one from the presidential election year, and statistically significant, even though we have a sample size that is considerably smaller.

We have thus uncovered an empirical regularity that is to the best of our knowledge a novel one: 
turnout in state elections is affected by the distance to the state capital. There thus seems to be evidence in favor of the idea that electoral accountability might be related to the spatial distribution of a state's population relative to its capital city. However, assuming from this that the relationship that emerges from the county-level data would necessarily aggregate up to a link between state-level turnout and the isolation of the state capital would be incurring in the well-known ecological fallacy. As it turns out, there is a weakly negative link between turnout and the isolation of the capital, but this relationship turns out not to be statistically significant and, most crucially, rather dependent on the influence of New Jersey and Minnesota. (These are available upon request.) We thus cannot be confident that the link carries over to the aggregate state level.

In sum, we have established an empirical connection between isolated capital cities and greater levels of corruption across US states, consistent with the accountability view. We have also found direct evidence for that view, as different accountability mechanisms are related to the spatial distribution of population: distance from the capital reduces the coverage devoted by the media, as well as the knowledge and interest voters display, with respect to state politics, and it also reduces turnout in state elections. ${ }^{27}$

As a final note, it is worth remarking that the direct evidence linking isolated capital cities to lower accountability also gives us fresh perspective on the basic stylized fact that links them to greater corruption, and particularly so in light of the inherent limitations of our corruption measures. Insofar as our measures might also to some extent capture accountability rather than corruption per se, as we have noted, it is likely that the measured effect of isolated capitals on corruption would be an underestimate. The direct evidence on accountability suggests that our measures of corruption would actually underestimate the true degree of corruption, relatively speaking, in places with isolated capital cities.

\section{Capture and the Spatial Distribution of Population}

The evidence so far has been decisively in favor of the accountability view: isolated capital cities are associated with greater corruption, and both media and electoral accountability seem to be affected by the spatial distribution of population in ways that are consistent with that. It is still useful, however, to take a more direct look at the alternative capture view. It could still be the case that having a capital city that is removed from the major centers of population and economic activity does reduce the risk of political capture by special interests, but that these effects are swamped by the reduced scope for accountability associated with that isolation.

With that in mind, we look at data on contributions to state-level political campaigns, as a proxy for the role of those economic interests, to see if the patterns across states display differences related to the spatial separation between the centers of political power and economic activity. (The data on

\footnotetext{
${ }^{27}$ It is hard to disentangle empirically the extent to which each of these mechanisms may explain the link with corruption, particularly since they are likely to be correlated with each other - voter turnout will likely be affected by media coverage, and so on. A simple horse race between our variables suggests that the media play a relatively more prominent role (available upon request).
} 
contributions come from the National Institute on Money in State Politics, and are collected for the period 2001-2010, as the state coverage in previous electoral cycles is somewhat inconsistent.) The main question is whether those contributions are also affected by the spatial distribution of population.

As it turns out, there is a surprisingly strong positive correlation between contributions to state-level campaigns and the isolation of the state capital - that is, in the exact opposite direction of what would have been predicted by the capture hypothesis. This is what we see in Table 11. Columns (1)-(2) show that the results hold for the basic OLS specifications, which reproduce our preferred specifications for corruption, but substituting campaign contributions as our dependent variable. They are also quite substantial from a quantitative perspective: a one-standard-deviation increase in the isolation of the capital (as measured by AvgLogDistance ${ }_{n o t}$ ) would be associated with a $30 \%$ increase in contributions. Columns (3)-(4) then show that the results survive unscathed when we control for presidential campaign contributions (in the 2008 election cycle). These are very highly correlated with state-level contributions (the raw correlation is 0.87 ), and may thus help capture other factors leading to a high general propensity to engage in this form of political activity. ${ }^{28}$ Finally, Columns (5)-(6) show similar results when we again instrument for AvgLogDistance using the isolation of the centroid with respect to population, although the same is not true when the instrument is the isolation with respect to suitable land (Columns (7)-(8)).

\section{[TABLE 11 HERE]}

In sum, the argument that isolated capitals would prevent an undue influence of economically powerful groups seems not to be borne out by this admittedly rough exercise. Much to the contrary, it seems that they are actually associated with greater levels of campaign contributions. Based on the evidence from the previous subsections, one could thus speculate that, in the presence of lower media scrutiny and reduced involvement by voters, an isolated capital may open the way for a stronger role of money in shaping political outcomes.

\section{Isolated Capital Cities and the Provision of Public Goods}

Finally, since the evidence suggests that an isolated capital city is associated with lower levels of accountability and more widespread corruption, it is worth asking whether this pattern would also be reflected in a diminished provision of public goods. It is certainly plausible, and would be of particular concern, if that were indeed the case.

In order to investigate this possibility, we collect data from the US Statistical Abstract (2012 edition) on the pattern of expenditures by US states, and also on outcomes that might be related to the provision of public goods. Most of state government expenditures that might be directly ascribed to public good

\footnotetext{
${ }^{28}$ Interestingly, the concentration of population does not come out with a significant coefficient in a similar regression with presidential contributions as the dependent variable (available upon request). This seems consistent with the idea that the distribution of population around the capital city should not affect the level of engagement with politics at the federal level.
} 
provision fall under four categories: "Education," "Public Welfare," "Health," and "Hospitals." We thus compute the share of total spending devoted to these categories as a proxy for the resources that the state devotes to public good provision. We also compute the share devoted to "Government Administration," "Interest on General Debt," and "Other" as a proxy for what is not directly related to public good provision, although they could certainly be indirectly related. ${ }^{29}$

These measures do not say much about how effectively these resources are spent, of course. We thus also check proxies for the ultimate provision of public goods, which are affected directly by many factors other than state-level policy, but should nevertheless provide a useful piece of information for our purposes. Specifically, we use three measures that capture aspects of what should be affected by the type of public good expenditure we have defined: the "Smartest State" index (Morgan Quitno Corporation 2005), which aggregates twenty-one different measures of educational inputs and outcomes, the percentage of the population that has health insurance, and the log of the number of hospital beds per capita.

Table 12 displays the results using AvgLogDistance not $^{30}$ Columns (1)-(2) show isolated capital cities being significantly correlated with lower spending on public good provision, and with more spending on items not directly related to it. Column (3) then shows a correlation, significant at the $10 \%$ level, with lower levels of public good provision, summarized by the first principal component of the three measures. The estimates are quantitatively meaningful: a one-standard-deviation increase in isolation is associated with a drop of around 0.25-0.3 standard deviation in the distribution of spending, and similarly for public good provision. Columns (4)-(6) then display 2SLS specifications, again with the isolation of the centroid with respect to population as the instrument. The results are broadly consistent, although the coefficient for public good provision is now essentially zero. ${ }^{31}$

\section{[TABLE 12 HERE]}

Along with our previous evidence, this paints a picture of isolated capital cities associated with low accountability and corruption, with important detrimental effects on the state's performance as a provider of public goods.

\section{Concluding Remarks}

We have explored the connections between the spatial distribution of population and corruption, in the context of US states and their often relatively isolated capital cities. We contrasted two very different

\footnotetext{
${ }^{29}$ The "public good" category accounts for, on average, just under two thirds of total expenditures, although it varies from as low as $51 \%$ (Louisiana) to as high as $77 \%$ (Tennessee). The unrelated category comprises about one sixth of total expenditures, on average, varying from about $11 \%$ (Tennessee) to about $28 \%$ (North Dakota).

${ }^{30}$ We use the control variables from our preferred specification for the baseline results in Table 1, except that we add ethnic fractionalization in order to take into account the standard result that it seems to affect the provision of public goods (eg Alesina, Baqir and Easterly 1999).

${ }^{31}$ The results are very similar if we use AvgLogDistance ${ }_{a d j}$ instead, which we do not report for the sake of brevity. The signs of the coefficients consistent throughout. In addition, the 2SLS results are rather imprecisely estimated, but the point estimates, though smaller than their OLS counterparts, are not too far from them.
} 
hypotheses that have been raised regarding those connections - the accountability view that sees public officials being subject to less scrutiny when the capital city is isolated, and the capture view that posits spatial separation between political power and major economic centers as a bulwark against capture by economic interests. We first established the stylized fact that isolated capital cities are robustly associated with greater levels of corruption - in line with the accountablity view - and showed that it holds when we use the location of the state centroid and the spatial distribution of land suitability for agriculture as sources of exogenous variation for the isolation of the capital.

We then looked for direct evidence for different accountability mechanisms. We showed that newspapers tend to provide greater coverage of state politics when their audience is more concentrated around the state capital, that voters are less knowledgeable and interested in state politics when they live far from the capital, and that voter turnout in state elections (but not in presidential ones) tends to be lower in areas that are relatively far from the capital. In a marked contrast, the direct evidence on the capture view goes in the exact opposite direction: campaign contributions are actually higher in states with isolated capitals, belying the fear that having the capital in a major economic center would lead to a greater risk of capture of state politics by economic interests. Finally, we provided some suggestive evidence that the pattern of low accountability induced by isolated capital cities also translates into worse provision of public goods.

It is interesting to speculate about this connection going into the future, as the so-called "death of distance" (Cairncross 1997) brought about by changes in communications technologies could mean that the isolation of capital cities would become relatively less important. Associated with that, the ongoing revolution in media technology, and in particular the retreat of newspapers, could mean that the specific media accountability mechanism we detect might also wither. While this is without question an interesting topic for future research, we believe there is reason to think that this need not be the case. Casual observation does not suggest that online media are necessarily immune to a bias towards local coverage - consistent with the idea of demand-driven bias. What is more, there could be forces operating in the other direction: newspapers are still the crucial element for media accountability at the state level, and as they cut back, the coverage of state politics may be one of the first on the chopping block. This could be especially so when the capital is isolated - precisely because newspapers need to focus on what is most interesting for their dwindling readership. ${ }^{32}$ On balance, it is at least unclear what will be the outcome of these forces.

From a broader perspective, our evidence sheds light on the long-run implications of institutional choices, and particularly their spatial content. Specifically, the importance of the choice of where to locate the capital city is highlighted both by the historical record in the US, where the issue was prominently discussed and fought over both at the state and federal levels, and by the many historical instances of

\footnotetext{
${ }^{32}$ Conversations with people in the newspaper industry suggest yet another related element pushing in that direction: it is easier to lay off the person who covers the state capitol and hardly ever shows up in the main newsroom, as opposed to those who work next to whoever decides on the cuts.
} 
capital relocations across different countries. We have shown one reason that makes it important, as it affects institutional performance along important dimensions such as the degree of accountability and the prevalence of corruption, even in a fully democratic context. In terms of policy, in particular, one is led to conclude that extra vigilance might be needed, when it comes to polities with isolated capital cities, in order to counteract their tendency towards reduced accountability. Put simply, watchdogs need to bark louder when there is a higher chance that people are not paying much attention.

In terms of future research, this provides further evidence that spatial distributions - of people, preferences, economic activity, etc. - matter for politico-economic outcomes, as argued by Rodden (2010). We also add the perspective that some places in space are different from others in that they occupy particularly important positions, institutionally or otherwise. We hope more effort will be devoted to understanding the implications of that.

\section{References}

Ades, Alberto F. and Edward L. Glaeser (1995). "Trade and Circus: Explaining Urban Giants." Quarterly Journal of Economics 110(1): 195-227.

Alesina, Alberto, Reza Baqir, and William Easterly (1999). "Public Goods and Ethnic Divisions." Quarterly Journal of Economics 114 (4): 1243-1284.

Alt, James E. and David Dreyer Lassen (2003). "The Political Economy of Institutions and Corruption in American States." Journal of Theoretical Politics 15(3):341-365

Alt, James E. and David Dreyer Lassen (2008). "Political and Judicial Checks on Corruption: Evidence from American State Governments." Economics and Politics 20(1): 33-61.

Alt, James E. and David Dreyer Lassen (2011). "Enforcement and Public Corruption: Evidence from US States." Harvard University (unpublished).

Boylan, Richard T. and Cheryl X. Long (2002). "Measuring Public Corruption in the American States: A Survey of State House Reporters." State Politics 83 Policy Quarterly 3(4): 420-438.

Burden, Barry C. (2000). "Voter Turnout and the National Election Studies." Political Analysis 8(4): 389-398.

Cairncross, Frances (1997). The Death of Distance: How the Communications Revolution is Changing Our Lives. Boston, MA: Harvard Business School Press.

Campante, Filipe R. and Quoc-Anh Do (2010). "A Centered Index of Spatial Concentration: Expected Influence Approach and Application to Population and Capital Cities." Harvard Kennedy School (unpublished).

Campante, Filipe R., Quoc-Anh Do and Bernardo Guimaraes (2012) "Isolated Capital Cities and Misgovernance: Theory and Evidence." Harvard Kennedy School (unpublished).

Dandoy, Regis (2010). "Explaining Turnout in Regional Elections (1980-2010)." Presented at the Midwest Political Science Association Conference Chicago, 22-25 April.

Davis, James C. and J. Vernon Henderson (2003). "Evidence on the Political Economy of the Urbanization Process." Journal of Urban Economics 53(1): 98-125.

Druckmann, James N. (2005). "Media Matter: How Newspapers and Television News Cover Campaigns and Influence Voters." Political Communication 22: 463-481 
Fisman, Raymond and Roberta Gatti (2002). "Decentralization and Corruption: Evidence from U.S. Federal Transfer Programs." Public Choice 113(1-2): 25-35.

Galiani, Sebastian and Sukkoo Kim (2011). "Political Centralization and Urban Primacy: Evidence form National and Provincial Capitals in the Americas." In: Dora L. Costa and Naomi R. Lamoreaux (eds.), Understanding Long-Run Economic Growth: Geography, Institutions, and the Knowledge Economy, Chicago: University of Chicago Press.

Gentzkow, Matthew (2006). "Television and Voter Turnout." Quarterly Journal of Economics 121(3): 931-972.

Gentzkow, Matthew, Edward L. Glaeser, and Claudia Goldin (2005). "The Rise of the Fourth Estate: How Newspapers Became Informative and Why It Mattered." In: Edward L. Glaeser and Claudia Goldin (eds.) Corruption and Reform: Lessons from America's Economic History, Cambridge, MA: National Bureau of Economic Research.

Gentzkow, Matthew and Jesse M. Shapiro (2010). "What Drives Media Slant? Evidence from U.S. Daily Newspapers" Econometrica 78(1): 35-71.

Glaeser, Edward L. and Raven E. Saks (2006). "Corruption in America." Journal of Public Economics 90: 1053-1072.

Gordon, Sanford C. (2009). "Assessing Partisan Bias in Federal Public Corruption Prosecutions." American Political Science Review 103(4): 534-554.

Hearl, Derek J., Ian Budge, and Bernard Pearson (1996). "Distinctiveness of regional voting: A comparative analysis across the European Community (1979-1993)." Electoral Studies 15(2): 167-182.

Holbrook, Thomas M. and Emily Van Dunk (1993). "Electoral Competition in the American States." American Political Science Review 87(4): 955-962.

King, James D. (1989). "Interparty Competition in the American States: An Examination of Index Components." The Western Political Quarterly 42(1): 83-92.

Lachman, Seymour and Robert Polner (2006). Three Men in a Room: The Inside Story of Power and Betrayal in an American Statehouse. New York, NY: The New Press.

Lim, Claire S.H., James M. Snyder, Jr, and David Stromberg (2010). "Measuring Media Influence on U.S. State Courts." Stanford GSB (unpublished).

Maxwell, Amanda E. and Richard F. Winters (2005). "Political Corruption in America." Dartmouth College (unpublished).

Meier, Kenneth J. and Thomas M. Holbrook (1992). “'I seen my opportunities and I took'em:' Political Corruption in the American States." Journal of Politics 54: 135-155.

Meier, Kenneth J. and Thomas Schlesinger (2002). "Variations in Corruption among the American States." In: Arnold Heidenheimer and Michael Johnson, (eds.), Political Corruption: Concepts and Contexts, New Brunswick, N.J.: Transaction Publishers.

Morgan Quitno Corporation (2005), Education State Rankings : 2005-2006. Lawrence, KS: Morgan Quitno.

Mullainathan, Sendhil and Andrei Shleifer (2005). "The Market for News." American Economic Review 95(4): 1031-1053.

Ramankutty, Navin, Jonathan A. Foley, John Norman, and Kevin McSweeney (2002). "The Global Distribution of Cultivable Lands: Current Patterns and Sensitivity to Possible Climate Change." Global Ecology and Biogeography 11(5): 377-392.

Redlich, Norman (2006). "Foreword." In: Seymour Lachman and Robert Polner, Three Men in a Room: The Inside Story of Power and Betrayal in an American Statehouse. New York, NY: The New Press. 
Rodden, Jonathan (2010). "The Geographic Distribution of Political Preferences." Annual Review of Political Science 13: 321-340.

Rose-Ackerman, Susan (1999). Corruption and Government: Causes, Consequences, and Reform. Cambridge, UK: Cambridge University Press.

Saiz, Albert and Uri Simonsohn (2011). "Proxying for Unobservable Variables with Internet Document Frequency." Journal of the European Economic Association (forthcoming).

Shelley, Fred M. (1996). Political Geography of the United States. New York, NY: Guilford Press.

Shufeldt, Gregory and Patrick Flavin (2011). "Reevaluating Two Measures of Inter-Party Competition in the American States." Baylor (unpublished).

Snyder, James M., Jr. and David Stromberg (2010). "Press Coverage and Political Accountability." Journal of Political Economy 118(2): 355-408.

Stein, Mark (2008). How the States Got Their Shapes. New York: Collins (Smithsonian Books).

Stock, James H. and Motohiro Yogo (2005). "Testing for Weak Instruments in Linear IV Regression." In: Donald W. K. Andrews and James H. Stock (eds.), Identification and Inference for Econometric Models: Essays in Honor of Thomas Rothenberg, Cambridge, UK: Cambridge University Press, $2005,80108$.

Treisman, Daniel (2007). "What Have We Learned About the Causes of Corruption from Ten Years of Cross-National Empirical Research?" Annual Review of Political Science 10: 211-244.

Vinson, C. Danielle (2003) Local Media Coverage of Congress and Its Members: Through Local Eyes. Cresskill NJ, Hampton Press.

Wilson, James Q. (1966) "Corruption: The Shame of the States." Public Interest 2: 28-38.

Zagarri, Rosemarie (1987). The Politics of Size: Representation in the United States, 1776-1850. Ithaca, NY: Cornell University Press. 


\section{Data Appendix}

Here we describe the variables and corresponding data sources.

CISC We compute the different versions of the Centered Index of Spatial Concentration, as described in the text. Following Campante and Do (2010), we have the formula GCISC $C_{1}=\sum_{i} s_{1 i}\left(\alpha_{1} \log \left(d_{i}\right)+\beta_{1}\right)$, where $s_{1 i}$ is the share of the state's population living in county $i$ and $d_{i}$ is the distance between county $i$ 's centroid and the point of interest (capital or centroid or largest city). The parameters $\left(\alpha_{1}, \beta_{1}\right)$ are $\left(-\frac{1}{\log \left(d_{1}\right)}, 1\right)$, where $\bar{d}_{1}$ is the maximum distance, across all states, between a state's capital (or other point of interest) and another point in that state. By the same token, GCISC $C_{2}=\sum_{i} s_{2 i}\left(\alpha_{2} \log \left(d_{i}\right)+\beta_{2}\right)$, where $s_{2 i}$ is the share of the state's population living in county $i$, normalized by $\log \left(\bar{d}_{2}\right)$, where $\bar{d}_{2}$ is the maximum distance, for each state, between the state's capital (or other point of interest) and another point in that state. The parameters $\left(\alpha_{2}, \beta_{2}\right)$ are $(-1,1)$. In this way, GCISC $C_{2}$ controls for the state's size, while $G C I S C_{1}$ does not. ( $L C I S C$ replaces $\log (d)$ with $d$.) The population data are from the US Census, from 1920 to 2000. (As we go all the way back to 1920, we exclude Alaska and Hawaii, which were not states at the beginning of the period.) Centroid CISCs are calculated in similar fashion, with distances measured with respect to the state centroid

GCISC $_{1}$ 1920-1970: n= 48, Mean: 0.311, S.D.: 0.095, Min:0.158, Max: 0.577.

GCISC 2 1920-1970: n= 48, Mean: 0.203, S.D.: 0.073, Min:0.080, Max: 0.411.

GCISC $C_{1}$ centroid (population) 1920-1970: $\mathrm{n}=48$, Mean: 0.242, S.D.: 0.084, Min: 0.090, Max: 0.526.

Corruption Number of federal convictions for public corruption 1976-2002 relative to average population in the state 1976-2002, from the 1989, 1999 and 2002 issues of the Report to Congress on the activities and operations of the Public Integrity Section, issued by the Department of Justice. The data were generously shared by Ed Glaeser and Raven Saks (GS), and is further described in Glaeser and Saks (2006).

n= 50 , Mean: 0.275, S.D.: 0.132, Min: 0.073, Max: 0.625 .

Corruption (State Officials) Number of federal convictions of state officials for public corruption 1986-2011, obtained separately for each year from the Transactional Records Access Clearinghouse (TRACfed) at Syracuse University, per 100 state government employees (as of 1980). Specifically, using the "Analyzer - Data" tool at <http://tracfed.syr.edu/index/index.php?layer=cri $>$, we select for each state all the corresponding districts in the "Select geographical area" field, each individual year in the "Select fiscal year" field, and "Corruption(Govt Off)-State" in the "Select program area" field, and then count the number of convictions in the output file.

$\mathrm{n}=50$; Mean: 0.0304; S.D.: 0.0223; Min: 0; Max: 0.0874 .

Corruption (Exalead) Following Saiz and Simonsohn (2008), we use the Exalead (www.exalead.com) search tool to search for the word "corruption" near the name of the state (corruption NEAR name of state), and divide the number of hits by the number of hits for the name of the state alone. (In the case of Washington, we search for "Washington State".) The search was performed in September 2009. $\mathrm{n}=50$, Mean: 0.00023, S.D.: 0.00034, Min: 0.00004, Max: 0.00177. 
Income Median household income, from US Census. (GS)

\% College Share of the population aged 25 and up with four or more years of college, from US Census. (GS)

Population From Bureau of Economic Analysis (BEA). (GS)

Area From US Census.

$\mathrm{n}=50$; Mean: 70748; S.D.: 85987; Min: 1045; Max: 571951.

Maximum Distance Maximum distance between capital and county centroids, from US Census. n= 48; Mean: 388.1; S.D.: 180.1; Min: 42.8; Max: 824.7.

Share of government employment Number of government employees relative to total employment, from BEA. (GS)

\% Urban Urban population relative to total population in the state, from US Census. (GS)

Regional dummies US Census regions: South, Midwest, West, Northeast.

Racial dissimilarity Racial heterogeneity: Dissimilarity index $=1-\sum s_{i}^{2}$, where $s_{i}$ is the population share of group $i$. (GS)

Regulation index Component of economic freedom index published in 1999 by Clemson University, http://freedom.clemson.edu. (GS)

Share of value added in mining In 2007, from BEA.

Capital Share Population of capital city relative to total population in the state (1980), from US Census.

$\mathrm{n}=50$, Mean: 0.063, S.D.: 0.064, Min: 0.004, Max: 0.280.

Capital Largest Dummy equal to 1 is capital is largest city in the state.

n= 50, Mean: 0.34, S.D.: 0.478, Min: 0, Max: 1 .

Drug Cases Criminal defendants charged with "drug offenses" and commenced at US District Courts during the 12-month period ending in September 30, 2011, per 100,000 inhabitants (as of 2000). The number of cases is taken from Table D-3 in the 2011 Annual Report of the Director: Judicial Business of the United States Courts, available at http://www.uscourts.gov/Statistics/JudicialBusiness.aspx\#appTables $\mathrm{n}=$ 50, Mean: 6.351, S.D.: 6.379, Min: 1.040, Max: 37.845 . 
Land Suitability CISC (Centroid) We compute GCISC $C_{1}$ as described before, but with land suitability instead of populations. We use the gridded land suitability data (probability that each grid cell could be cultivated, based on climate and soil quality measurements) from the Atlas of the Biosphere published by the Center for Sustainability and the Global Environment (SAGE) at the University of Wisconsin-Madison (available at http://www.sage.wisc.edu/iamdata/grid_data_sel.php). (The original source of the data is Ramankutty et al (2002).) We match the grid with coordinates of US counties, so that we have the average land suitability for each county, and we use the distance from each county's centroid to the state centroid as our measure of distance.

n=48, Mean: 0.248, S.D.: 0.079, Min: 0.120, Max: 0.534.

Governor Salary Governor's annual compensation in 2008, from Alaska Department of Administration (available at http://doa.alaska.gov/dop/fileadmin/socc/pdf/bkgrnd_socc23.pdf).

n= 50, Mean: 128735, S.D.: 29316, Min: 70000, Max: 212179.

House Price Ratio Ratio between median housing list prices (per square foot) in the capital and in the state as a whole, from Zillow.com (searched in July 2012). Prices not available for Pierre (SD). $\mathrm{n}=49$; Mean: 1.027; S.D.: 0.356; Min: 0.289; Max: 1.934 .

Total Border Number of total miles of borders with another state (from Holmes 1998), with another country (from US Census, as reported in the US Statistical Abstract, 2012, Table 363), and of general coastline, including Great Lakes (from US Census, as reported in the US Statistical Abstract, 2012, Tables 361 and 364).

$\mathrm{n}=49$, Mean: 1039, S.D.: 480, Min: 103, Max: 2780.

Latitude and Longitude Latitude of northernmost internal point, longitude of westernmost internal point. (GS)

$\mathrm{n}=50$ and 50, Mean: 39.5 and 93.6, S.D.: 6.1 and 19.1, Min: 20.8 and 69.4, Max: 61.6 and 157.0.

Elevation Span Difference between state's highest and lowest point, in feet, from US Geological Survey.

n= 50, Mean: 5494, S.D.: 4736, Min: 345, Max: 20320.

Percentage of Water Area Percentage of state area that is inland water (i.e. surrounded by US land), from US Census.

$\mathrm{n}=50$, Mean: 2.97, S.D.: 3.06, Min: 0.20, Max: 17 .

Navigable Waterways Mileage of inland waterways, determined by including the length of channels 1) with a controlling draft of nine feet or greater, 2) with commercial cargo traffic reported for 1998 and 1999, but 3) were not offshore (i.e., channels in coastal areas included only the miles from the entrance channel inward). Channels within major bays are included (e.g., Chesapeake Bay, San Francisco Bay, Puget Sound, Long Island Sound, and major sounds and straits in southeastern Alaska). Channels in the Great Lakes are not included, but waterways connecting lakes and the St. Lawrence Seaway inside the United States are included. From US Army Corps of Engineers, available at 
http://www.statemaster.com/graph/trn_inl_wat_mil-transportation-inland-waterway-mileage. $\mathrm{n}=50$, Mean: 592.4, S.D.: 919.3, Min: 0, Max: 5497.

Share of Arable Land, 1950 Agricultural land as a share of total area, in 1950, from US Department of Agriculture.

$\mathrm{n}=48$, Mean: 0.616, S.D.: 0.218, Min: 0.107, Max: 0.984 .

Railroad Miles, 1870 Number of miles of railroad in operation during the year 1870, from US Statistical Abstract, 1878, Table 144.

$\mathrm{n}=45$, Mean: 1165, S.D.: 1202, Min: 0, Max: 4823.

Population, 1870 From US Census, as reported in US Statistical Abstract, 1878, Table 142. $\mathrm{n}=45$, Mean: 1361600, S.D.: 3773519, Min: 9118, Max: 25.4 million.

Coal Production, 1869 Tons of bituminous coal produced during 1869, from US Statistical Abstract, 1878, Table 150 .

n= 50, Mean: 344236, S.D.: 1216998, Min: 0, Max: 7798517.

Newspaper Coverage We start by searching for each of the terms under consideration - "state elections," "state budget," "state government," and the name of the governor - in the online archives of all of a state's newspapers that are available on NewsLibrary.com, for articles published between 01/01/2008 and 12/31/2009. (In the case of the governor's name, we search for the name of each governor during the sub-period, within that period, in which he or she was in office. We look for different combinations, including first name (or popular nickname) and last name, with or without middle initial. The full list is available upon request.) We also search for the neutral term "Monday". In order to compute the CISC of circulation, we use county-level circulation data from the U.S. County Penetration Report (Spring 2010), from the Audit Bureau of Circulations. Our final sample includes 436 newspapers, from 49 states (all except Montana).

"State Elections": n= 431, Mean: 997.8, S.D.: 900.2, Min: 0; Max: 7019.

Governor's name: $\mathrm{n}=436$, Mean: 719.8, S.D.: 736.5, Min: 0, Max: 5096.

Knowledge From the American National Election Studies (ANES), 1998 Pilot Study. We code a dummy equal to 1 if the respondent answers "Yes" to question 98P130 ("Do you happen to remember the names of the candidates for Governor who are running in the November election?") and provides a correct name in response to question 98P131 (which follows up asking for the name of such a candidate).

Interest From the American National Election Studies (ANES), 1998 Pilot Study. We code a dummy equal to 1 if the respondent reports to care "a great deal," "quite a bit," or "some" to question 98P105 ("How much attention did you pay to newspaper articles about the campaign for Governor?"). We limit the sample to individuals who report to have read newspapers at least once in the past week, in response to question 98P103 ("How many days in the past week did you read a daily newspaper?"). 
General Interest From the American National Election Studies (ANES), 1998 Pilot Study. We code a dummy equal to 1 if respondents answer "most of the time" or "some of the time' to question 98P376 ("Some people seem to follow what's going on in government and public affairs most of the time, whether there's an election going on or not. Others aren't that interested. Would you say you follow what's going on in government and public affairs most of the time, some of the time, only now and then, or hardly at all?).

General Level of Information From the American National Election Studies (ANES), 1998 Pilot Study. Question 98P440, asked of interviewers ("Respondent's general level of information about politics and public affairs seemed: 1 Very high, 2 Fairly high, 3 Average, 4 Fairly low, 5 Very low "). We drop individuals whom the interviewers stated they could not rate (6).

Turnout in State Elections Total popular vote cast for candidates for governor at the county level in 1997-2000 (from David Leip's Atlas of US Presidential Elections, http://uselectionatlas.org), divided by total voting-age population in the county (from US Census in 2000).

n= 4986, Mean: 0.543, S.D.: 0.084, Min: 0.273, Max: 0.849 .

State Campaign Contributions Sum of campaign contributions to state office between 2001 and 2010, from the National Institute on Money in State Politics (available at www.followthemoney.org. $\mathrm{n}=50$, Mean: 102.4 million, S.D.: 135.81 million, Min: 9.9 million, Max: 824.9 million.

Presidential Campaign Contributions Total donations to presidential campaigns in 2008 cycle, from Federal Elections Commission (FEC) data compiled by the Center for Responsive Politics, available at http://www.opensecrets.org/pres08/pres_stateAll.php?list=all

$\mathrm{n}=50$, Mean: 17.5 million, S.D.: 27.96 million, Min: 0.41 million, Max: 153.2 million.

Public Good Expenditures Share of state general expenditures assigned to the categories "Education," "Public Welfare," "Health," and "Hospitals," from US Statistical Abstract 2012, Table 454.

n= 50, Mean: 0.654, S.D.: 0.074, Min: 0.366, Max: 0.766 .

Other Expenditures Share of state general expenditures assigned to the categories "Governmental Administration," "Interest on General Debt," and "Other," from US Statistical Abstract 2012, Table 454. n= 50, Mean: 0.179, S.D.: 0.056, Min: 0.109, Max: 0.400.

Public Good Provision First principal component of: "Smartest State" index, from Morgan Quitno Corporation (2005); \% Insured: 100 - Persons Without Health Insurance Coverage in 2008-2009 (Percent Total) from US Statistical Abstract 2012, Table 156; and log of Hospital Beds in 2009, from US Statistical Abstract 2012, Table 194 (divided by population).

$\mathrm{n}=50$, Mean: 0.237, S.D.: 1.232, Min: -1.944, Max: 3.494 . 
Table 1. Corruption and Isolation of the Capital City: Avg Log Distance

\begin{tabular}{|c|c|c|c|c|c|c|c|c|}
\hline Dep. Var.: Corruption & (1) & (2) & (3) & (4) & (5) & (6) & (7) & (8) \\
\hline \multirow{2}{*}{ AvgLogDistance $_{\text {not }}$} & $0.4439 * * *$ & $1.1166 * * *$ & $1.0307 * * *$ & $0.7932 * * *$ & & & & \\
\hline & {$[0.140]$} & [0.247] & {$[0.322]$} & {$[0.276]$} & & & & \\
\hline AvgLogDistance $_{\text {adj }}$ & & & & & [0.168] & {$[0.190]$} & {$[0.200]$} & [0.223] \\
\hline Basic Control Variables & & $\mathrm{X}$ & $\mathrm{X}$ & $\mathrm{X}$ & & $\mathrm{x}$ & $\mathrm{X}$ & $\mathrm{x}$ \\
\hline Control Variables I & & & $\mathrm{X}$ & $\mathrm{X}$ & & & $\mathrm{X}$ & $\mathrm{X}$ \\
\hline Control Variables II & & & & $\mathrm{X}$ & & & & $\mathrm{X}$ \\
\hline Observations & 48 & 48 & 48 & 48 & 48 & 48 & 48 & 48 \\
\hline R-squared & 0.114 & 0.465 & 0.532 & 0.609 & 0.232 & 0.406 & 0.525 & 0.598 \\
\hline
\end{tabular}

Robust standard errors in brackets. OLS regressions. Dependent variable: Corruption = Federal convictions for corruption-related crime relative to population, avg. 1976-2002. Independent variables as of 1970 (AvgLogDistance average 1920-1970). Basic Control Variables: Log Area and Log Maximum Distance

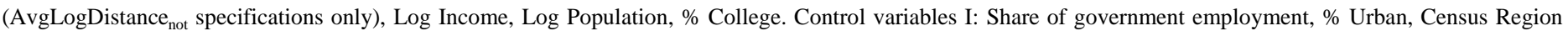
dummies. Control variables II: Racial dissimilarity, Regulation index, Share of value added in mining. ${ }^{* * *} \mathrm{p}<0.01,{ }^{* *} \mathrm{p}<0.05,{ }^{*} \mathrm{p}<0.1$.

Table 2. Corruption and Isolation of the Capital City: Robustness

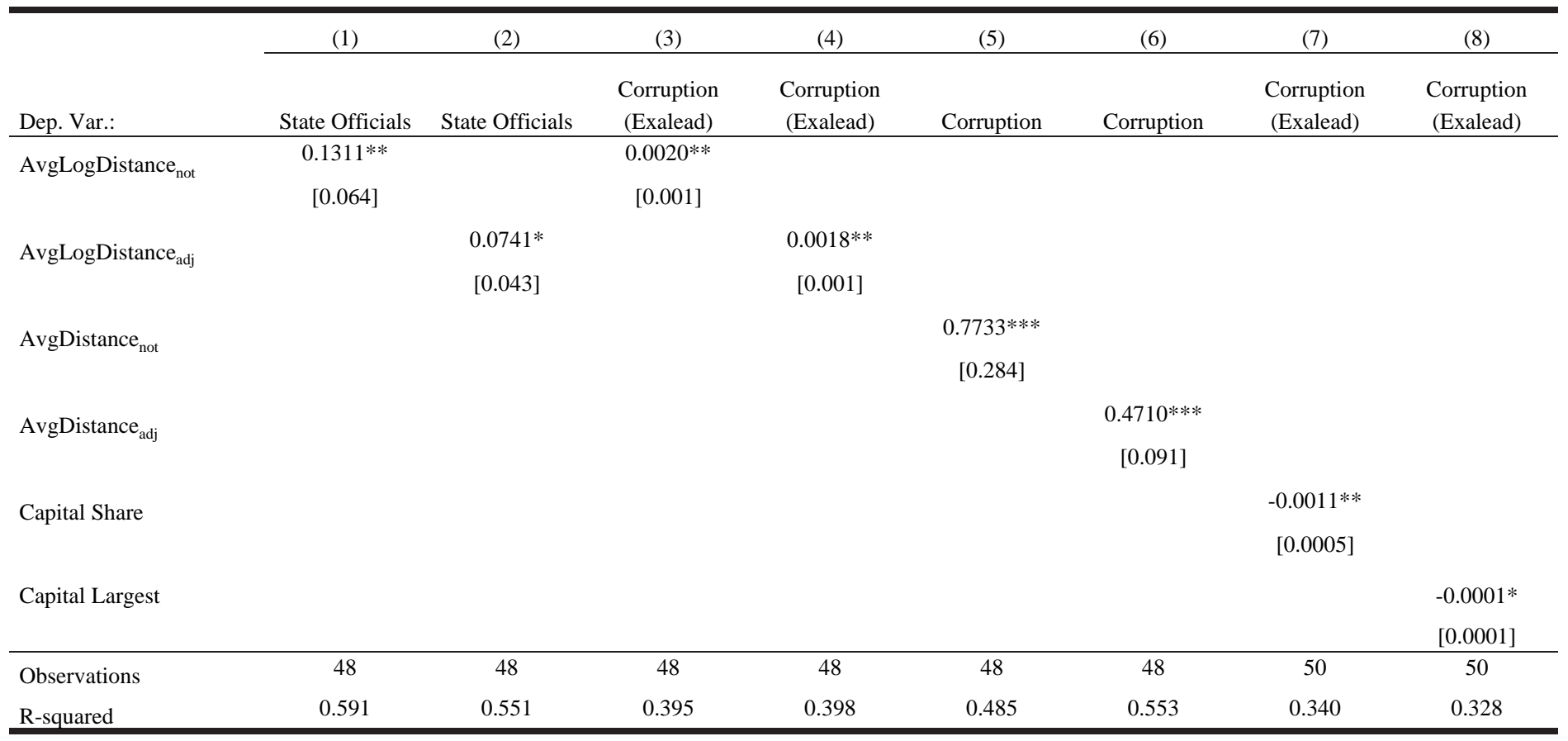

Robust standard errors in brackets. OLS regressions; Columns (1)-(2): Weighted OLS regressions (Weight $=0.0000001+$ st. dev. of conviction sample). Dependent variables: State Officials = Federal convictions of state public officials for corruption-related crime per 100 state government employees, avg. 1986-2011. Corruption (Exalead) = Number of search hits for "corruption" close to state name divided by number of search hits for state name, using Exalead search tool (in 2009). Corruption $=$ Federal convictions for corruption-related crime relative to population, avg. 1976-2002. Independent variables as of 1970 (AvgLogDistance avg. 19201970) in Columns (1)-(2) and (5)-(6), as of 2000 (AvgLogDistance avg. 1920-2000) in Columns (3)-(4) and (7)-(8). Control variables: Log Area and Log Maximum Distance (for AvgLogDistance ${ }_{\text {not }}$ specifications only), Log Income, Log Population, \% College, Share of government employment, \% Urban, Census Region dummies. ${ }^{* *} \mathrm{p}<0.01,{ }^{* *} \mathrm{p}<0.05,{ }^{*} \mathrm{p}<0.1$. 
Table 3. "Placebo" Tests

\begin{tabular}{|c|c|c|c|c|c|c|c|c|}
\hline & (1) & (2) & (3) & (4) & (5) & (6) & (7) & (8) \\
\hline Dep. Var.: & Corruption & Corruption & Corruption & Corruption & Drug Cases & Drug Cases & Drug Cases & Drug Cases \\
\hline \multirow[t]{2}{*}{ AvgLogDistance $_{\text {not }}$ (largest city) } & 0.4817 & -0.0109 & & & & & & \\
\hline & [0.298] & [0.336] & & & & & & \\
\hline \multirow[t]{2}{*}{ AvgLogDistance $_{\text {adj }}$ (largest city) } & & & 0.2564 & -0.2019 & & & & \\
\hline & & & [0.222] & [0.242] & & & & \\
\hline \multirow{2}{*}{ AvgLogDistance $_{\text {not }}$} & & $1.0366^{* * *}$ & & & -4.4612 & & -3.9185 & \\
\hline & & [0.378] & & & [13.799] & & [9.765] & \\
\hline \multirow[t]{2}{*}{ AvgLogDistance $_{\text {adj }}$} & & & & $0.8921^{* * *}$ & & 1.0907 & & -9.5891 \\
\hline & & & & [0.236] & & [9.201] & & [8.288] \\
\hline Observations & 48 & 48 & 48 & 48 & 48 & 48 & 44 & 44 \\
\hline R-squared & 0.422 & 0.532 & 0.370 & 0.532 & 0.339 & 0.322 & 0.394 & 0.417 \\
\hline
\end{tabular}

Robust standard errors in brackets. OLS regressions. Dependent variables: Corruption = Federal convictions for corruption-related crime relative to population, avg. 1976-2002; Drug Cases = Criminal defendants commenced in federal courts, 2011. Independent variables as of 1970 (AvgLogDistance avg. 1920-1970) for columns (1)-(4), as of 2000 (AvgLogDistance avg. 1920-2000) in Columns (5)-(8). Control variables: Log Area and Log Maximum Distance (for AvgLogDistance specifications only), Log Income, Log Population, \% College, Share of government employment, \% Urban, Regional dummies. Columns (7)-(8) exclude Mexico border states (CA, AZ, NM, TX). *** $\mathrm{p}<0.01, * * \mathrm{p}<0.05$, $* \mathrm{p}<0.1$.

Table 4. Pairwise Correlations between (Suitability) Centroid Avg Log Distance and Predetermined Variables

\begin{tabular}{|c|c|c|c|c|}
\hline Variable & $\begin{array}{c}\text { (1) } \\
\text { Raw Centroid } \\
\text { AvgLogDistance }_{\text {not }} \\
\text { (population) }\end{array}$ & $\begin{array}{c}\text { (2) } \\
\text { Raw Centroid } \\
\text { AvgLogDistance }_{\text {not }} \\
\text { (land suitability) }\end{array}$ & $\begin{array}{c}\text { (3) } \\
\text { Conditional } \\
\text { Centroid } \\
\text { AvgLogDistance }_{\text {not }} \\
\text { (population) }\end{array}$ & $\begin{array}{c}\text { (4) } \\
\text { Conditional } \\
\text { Centroid } \\
\text { AvgLogDistance }_{\text {not }} \\
\text { (land suitability) }\end{array}$ \\
\hline \multirow[t]{2}{*}{ Log Area } & $0.9571^{* * *}$ & $0.9771^{* * *}$ & - & - \\
\hline & {$[0.0000]$} & {$[0.0000]$} & & \\
\hline \multirow[t]{2}{*}{ Log Max Distance } & $0.9145^{* * *}$ & $0.9391^{* * *}$ & - & - \\
\hline & {$[0.0000]$} & {$[0.0000]$} & & \\
\hline \multirow[t]{2}{*}{ Log Total Border } & $0.8828^{* * *}$ & $0.9190 * * *$ & 0.0302 & 0.0744 \\
\hline & {$[0.0000]$} & {$[0.0000]$} & {$[0.8387]$} & {$[0.6151]$} \\
\hline \multirow[t]{2}{*}{ Latitude } & -0.0644 & -0.1466 & 0.0242 & -0.0203 \\
\hline & {$[0.6602]$} & [0.3199] & {$[0.8703]$} & [0.8912] \\
\hline \multirow[t]{2}{*}{ Longitude } & $0.5163^{* * *}$ & $0.7195^{* * *}$ & 0.0488 & -0.0150 \\
\hline & {$[0.0002]$} & {$[0.0000]$} & {$[0.7418]$} & [0.9192] \\
\hline \multirow[t]{2}{*}{ Log Distance to DC } & $0.5709 * * *$ & $0.6340 * * *$ & -0.0014 & -0.0482 \\
\hline & {$[0.0000]$} & {$[0.0000]$} & [0.9923] & {$[0.7450]$} \\
\hline \multirow[t]{2}{*}{ Date of Statehood } & $0.5271^{* * *}$ & $0.6255^{* * *}$ & -0.0694 & -0.0522 \\
\hline & {$[0.0001]$} & {$[0.6255]$} & {$[0.6395]$} & {$[0.7246]$} \\
\hline \multirow[t]{2}{*}{ Log Elevation Span } & $0.3564 * *$ & $0.4250 * * *$ & -0.1100 & -0.0629 \\
\hline & [0.0129] & {$[0.0026]$} & {$[0.4566]$} & [0.6713] \\
\hline \multirow[t]{2}{*}{ Percentage of Water Area } & $-0.5538 * * *$ & $-0.5611 * * *$ & -0.1357 & -0.0354 \\
\hline & {$[0.0000]$} & {$[0.0000]$} & {$[0.3579]$} & [0.8113] \\
\hline \multirow[t]{2}{*}{ Log Navigable Waterways } & 0.0009 & -0.0793 & 0.1037 & -0.0240 \\
\hline & [0.9951] & {$[0.5922]$} & {$[0.4832]$} & {$[0.8712]$} \\
\hline \multirow[t]{2}{*}{ Share of Arable Land (1950) } & 0.1254 & 0.1176 & -0.0821 & -0.0582 \\
\hline & {$[0.3957]$} & {$[0.4258]$} & {$[0.5790]$} & {$[0.6945]$} \\
\hline \multirow[t]{2}{*}{ Log Railroad Miles (1870) } & -0.0877 & -0.2107 & 0.0369 & -0.0651 \\
\hline & {$[0.5667]$} & {$[0.1648]$} & {$[0.8099]$} & {$[0.6709]$} \\
\hline \multirow[t]{2}{*}{ Log Population (1870) } & -0.0895 & -0.2209 & 0.0793 & 0.0094 \\
\hline & {$[0.5586]$} & {$[0.1447]$} & {$[0.6048]$} & {$[0.9511]$} \\
\hline \multirow[t]{2}{*}{ Log Coal Production (1869) } & -0.0748 & -0.0593 & -0.2066 & $-0.2613^{*}$ \\
\hline & {$[0.6132]$} & {$[0.6887]$} & [0.1589] & {$[0.0728]$} \\
\hline
\end{tabular}

p-values in brackets. Columns (3)-(4): Residuals of regression of AvgLogDistance on Log Area, Log Maximum Distance, and regional dummies. $* * * \mathrm{p}<0.01,{ }^{* *} \mathrm{p}<0.05,{ }^{*} \mathrm{p}<0.1$. 
Table 5. Corruption and Isolation of the Capital City: Addressing Causality

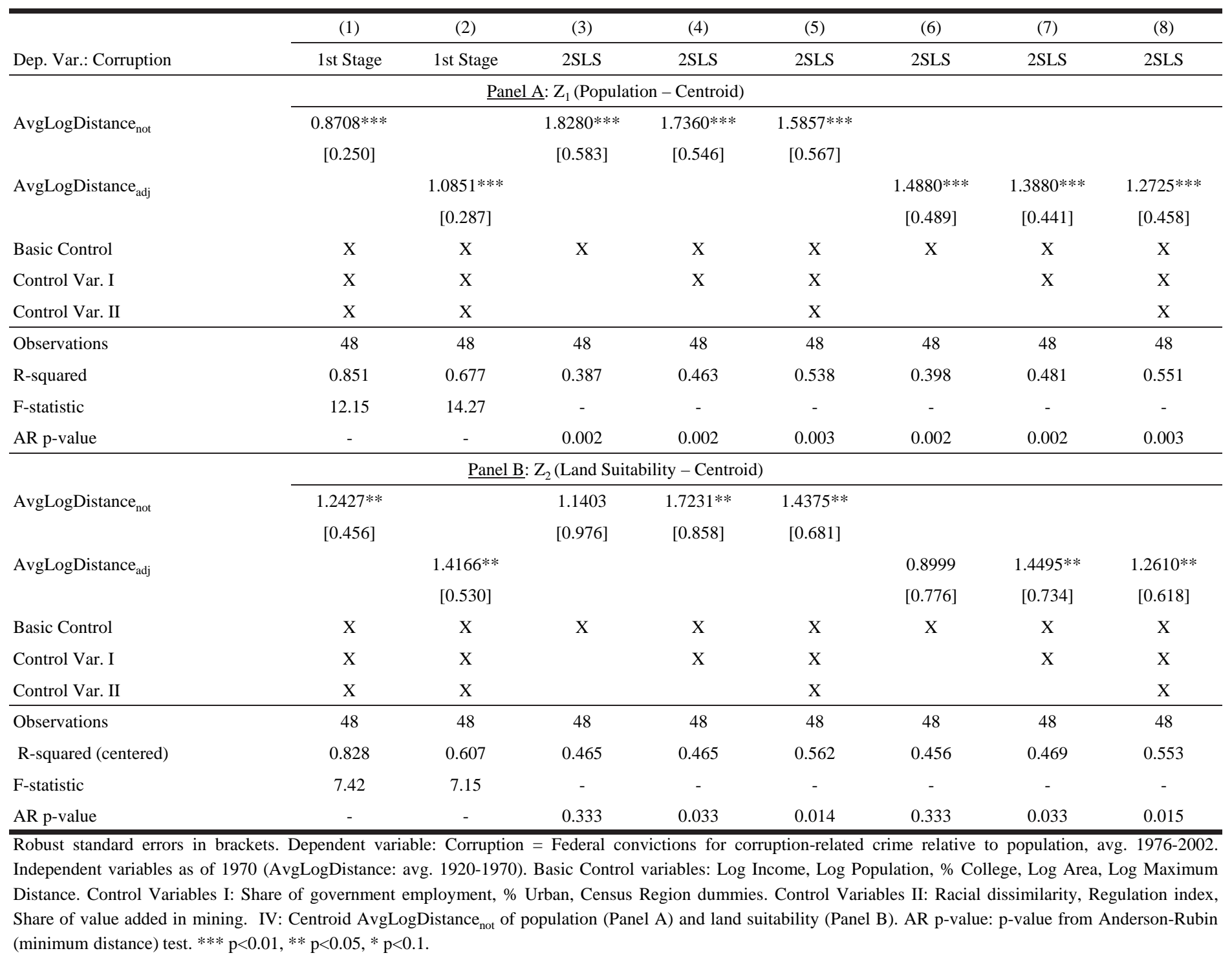

Table 6. Governors' Salaries and Isolation of the Capital City

\begin{tabular}{|c|c|c|c|c|c|c|c|c|}
\hline & (1) & (2) & (3) & (4) & (5) & (6) & (7) & (8) \\
\hline Dep. Var.: Log Governor Salary & OLS & OLS & OLS & OLS & $\begin{array}{c}\text { 2SLS } \\
\text { Population }\end{array}$ & $\begin{array}{c}\text { 2SLS } \\
\text { Population }\end{array}$ & $\begin{array}{c}\text { 2SLS } \\
\text { Land Suit. }\end{array}$ & $\begin{array}{c}\text { 2SLS } \\
\text { Land. Suit. }\end{array}$ \\
\hline \multirow[t]{2}{*}{ AvgLogDistance $_{\text {not }}$} & $1.3051^{* *}$ & $1.2453^{*}$ & & & $1.8045^{* *}$ & & $1.5467 *$ & \\
\hline & [0.563] & [0.709] & & & {$[0.711]$} & & [0.842] & \\
\hline \multirow[t]{2}{*}{ AvgLogDistance $_{\text {adj }}$} & & & $0.7715^{*}$ & 0.6453 & & $1.4708^{* * *}$ & & $1.2997^{*}$ \\
\hline & & & [0.429] & {$[0.462]$} & & {$[0.563]$} & & [0.701] \\
\hline \multirow[t]{2}{*}{ House Price Ratio } & -0.0053 & -0.0090 & -0.0223 & -0.0452 & 0.0178 & 0.0258 & 0.0055 & 0.0148 \\
\hline & [0.064] & {$[0.060]$} & {$[0.067]$} & {$[0.062]$} & {$[0.060]$} & {$[0.060]$} & [0.064] & [0.067] \\
\hline Observations & 47 & 47 & 47 & 47 & 47 & 47 & 47 & 47 \\
\hline R-squared & 0.629 & 0.639 & 0.524 & 0.556 & 0.627 & 0.639 & 0.635 & 0.643 \\
\hline AR p-value & - & - & - & - & 0.013 & 0.013 & 0.138 & 0.138 \\
\hline
\end{tabular}

Robust standard errors in brackets. Dependent variable: Log of Governor Salary (2008). Independent variables as of 2000 (AvgLogDistance: avg. 1920-2000).

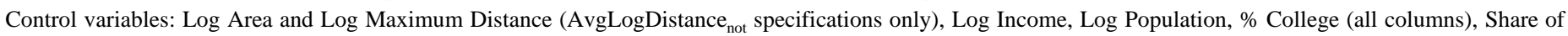

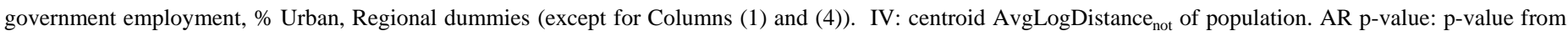
Anderson-Rubin (minimum distance) test. Sample excludes South Dakota, for which data on house prices is not available. ${ }^{* * *} \mathrm{p}<0.01,{ }^{* *} \mathrm{p}<0.05,{ }^{*} \mathrm{p}<0.1$. 
Table 7. Newspaper Coverage of State Politics and the Concentration of Circulation around the Capital

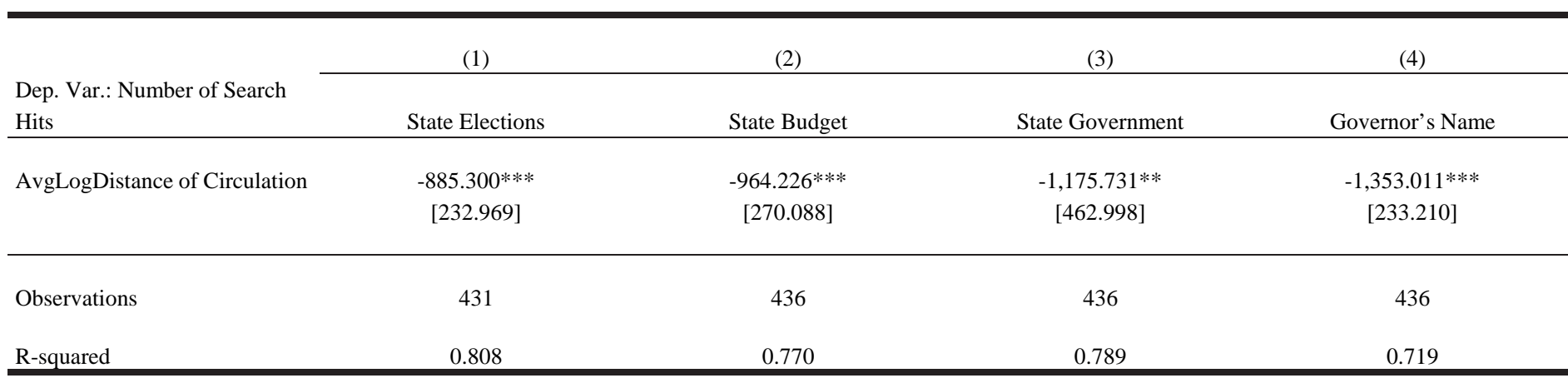

Robust standard errors in brackets. OLS regressions. Dependent variable: Number of search hits for each term in NewsLibrary.com (01/01/2008 to 12/31/2009).

Control variables: Log of daily circulation, Number of search hits for "Monday”, state fixed effects. ${ }^{* * *} \mathrm{p}<0.01, * * \mathrm{p}<0.05, * \mathrm{p}<0.1$.

Table 8. Media Coverage and Isolation of the Capital City

(1)

Circ. Weighted

AvgLogDistance

Weighted

$-2.1841$

(3)

(4)

(5)

(6)

Dep. Var.: Media Coverage

$-2.3921$

[3.285]

[3.379]

[3.285]

AvgLogDistance $_{\text {adj }}$

$-5.2566 * *$

$-3.6317 *$

[2.529]

[2.589]

[2.169]

Observations

47

47

47

47

46

46

AR p-value

$-$

$-$

$-$

$-$

0.115

0.115

R-squared

0.460

0.451

0.246

0.237

0.554

0.570

Robust standard errors in brackets. OLS regressions except where noted. Dependent variable: First principal component of weighted search hits for each of the terms in Table 7 (weighted by newspaper circulation or AvgLogDistance-weighted newspaper circulation, as indicated), divided by hits for “Monday”. Independent variables as

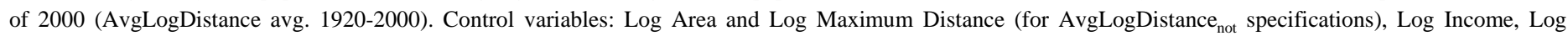
Population, \% College, Share of government employment, Regional dummies, Dummy for election in 2008-2009. Columns (5)-(6) exclude Rhode Island. The state of

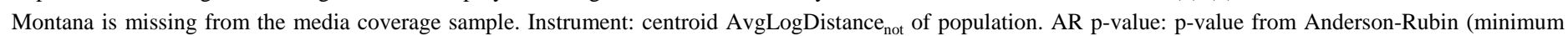
distance) test. $* * * \mathrm{p}<0.01, * * \mathrm{p}<0.05, * \mathrm{p}<0.1$. 


\begin{tabular}{|c|c|c|c|c|c|c|}
\hline & (1) & (2) & (3) & (4) & (5) & (6) \\
\hline Dep. Var.: & Knowledge & Knowledge & Interest & Interest & Gen. Interest & Gen. Interest \\
\hline & [0.0205] & {$[0.0252]$} & {$[0.0227]$} & {$[0.0288]$} & {$[0.0218]$} & {$[0.0275]$} \\
\hline Individual Controls & & $\mathrm{X}$ & & $\mathrm{X}$ & & $\mathrm{X}$ \\
\hline Observations & 780 & 780 & 652 & 648 & 780 & 776 \\
\hline Mean of dep. variable & 0.662 & 0.662 & 0.403 & 0.403 & 0.590 & 0.590 \\
\hline Pseudo R-squared & 0.033 & 0.172 & 0.021 & 0.160 & 0.014 & 0.207 \\
\hline
\end{tabular}

Robust standard errors in brackets, clustered by county. Probit regressions, marginal effects reported. Dependent variables: Knowledge = Dummy for knowing name of at least one candidate in gubernatorial elections; Interest = Dummy for caring “a great deal," "quite a bit," or "some” about newspaper articles regarding gubernatorial elections (conditional on reading newspapers); General Interest = Dummy for reporting interest in government and public affairs "most of the time" or "some of the time”. County Controls: population, percent urban, population density, percent non-White, median age, median income, and median schooling (from 1990 Census); Individual Controls: dummies for age, occupation, sex, income, and political party identification, and number of children and general level of information (from ANES). All columns include state fixed effects. ${ }^{* * *} \mathrm{p}<0.01,{ }^{* *} \mathrm{p}<0.05,{ }^{*} \mathrm{p}<0.1$.

Table 10. Distance to the Capital and Turnout in State Elections

Dep. Var.:

Turnout in State Elections
$(1)$

(2)

All Years
(3)

All Years
(4)

(5)

All Years

Presid. Year

\begin{tabular}{|c|c|c|c|c|c|c|}
\hline \multirow[t]{2}{*}{ LogDistance Capital } & $-0.0137 * * *$ & $-0.0175 * * *$ & & $-0.0169 * * *$ & -0.0070 & $-0.0365^{* *}$ \\
\hline & [0.0032] & [0.0027] & & {$[0.0027]$} & [0.0048] & [0.0069] \\
\hline \multirow[t]{2}{*}{ LogDistance Centroid } & & & $-0.0093 * * *$ & -0.0018 & & \\
\hline & & & {$[0.0028]$} & [0.0027] & & \\
\hline Control Variables & & $\mathrm{X}$ & $\mathrm{X}$ & $\mathrm{X}$ & $\mathrm{X}$ & $\mathrm{X}$ \\
\hline Observations & 3081 & 3027 & 3027 & 3027 & 553 & 364 \\
\hline R-squared & 0.761 & 0.836 & 0.829 & 0.836 & 0.746 & 0.796 \\
\hline
\end{tabular}

Robust standard errors in brackets. OLS regressions. Dependent variable: Turnout in state election, county-level (1997-2000). Independent variables: Log Distance to Capital, Log Distance to Centroid. Control variables: Log density, \% High School and above, Log Median Household Income, state fixed effects (all columns), Poverty Rate, Gini coefficient, Racial fractionalization, Religious fractionalization, Shares of population under 5, 5-17, 18-24, 25-44, 45-64, 65-84, 85 and above, all from 2000 Census. ${ }^{* * *} \mathrm{p}<0.01,{ }^{* *} \mathrm{p}<0.05,{ }^{*} \mathrm{p}<0.1$. 


\begin{tabular}{|c|c|c|c|c|c|c|c|c|}
\hline & (1) & (2) & (3) & (4) & (5) & (6) & (7) & (8) \\
\hline Dep. Var.: Log State Contributions & OLS & OLS & OLS & OLS & $\begin{array}{c}\text { 2SLS } \\
\text { Population }\end{array}$ & $\begin{array}{c}\text { 2SLS } \\
\text { Population }\end{array}$ & $\begin{array}{c}\text { 2SLS } \\
\text { Land Suit. }\end{array}$ & $\begin{array}{c}\text { 2SLS } \\
\text { Land. Suit. }\end{array}$ \\
\hline \multirow[t]{2}{*}{ AvgLogDistance $_{\text {not }}$} & $3.0146 * * *$ & & $2.4782 * *$ & & $5.0364 * * *$ & & 1.6361 & \\
\hline & {$[0.942]$} & & {$[1.080]$} & & {$[1.679]$} & & [2.339] & \\
\hline \multirow[t]{2}{*}{ AvgLogDistance $_{\text {adj }}$} & & $2.4241 * * *$ & & $1.9627 * *$ & & $4.0473 * * *$ & & 1.3751 \\
\hline & & {$[0.788]$} & & {$[0.856]$} & & {$[1.372]$} & & {$[1.988]$} \\
\hline \multirow[t]{2}{*}{ Log Presid. Contributions } & & & 0.3171 & $0.3407^{*}$ & 0.1854 & 0.2163 & $0.3605^{* *}$ & $0.3670^{* *}$ \\
\hline & & & {$[0.207]$} & {$[0.200]$} & {$[0.216]$} & {$[0.206]$} & {$[0.173]$} & {$[0.171]$} \\
\hline Observations & 48 & 48 & 48 & 48 & 48 & 48 & 48 & 48 \\
\hline R-squared & 0.903 & 0.899 & 0.910 & 0.907 & 0.897 & 0.896 & 0.909 & 0.907 \\
\hline AR p-value & - & - & - & - & 0.002 & 0.002 & 0.505 & 0.505 \\
\hline
\end{tabular}

Robust standard errors in brackets. Dependent variable: Log of Campaign Contributions to state-level campaigns, 2001-2010. Independent variables as of 2000 (AvgLogDistance: avg. 1920-2000). Control variables (as of 2000): Log of Campaign Contributions to presidential campaigns (2008): Log Area and Log Maximum Distance (AvgLogDistance ${ }_{\text {not }}$ specifications only), Log Income, Log Population, \% College (all columns), Share of government employment, \%Urban, Regional

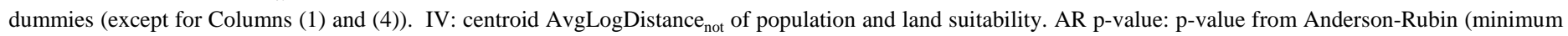
distance) test. ${ }^{* * *} \mathrm{p}<0.01,{ }^{* *} \mathrm{p}<0.05,{ }^{*} \mathrm{p}<0.1$.

Table 12. Public Goods and Isolation of the Capital City

\begin{tabular}{|c|c|c|c|c|c|c|}
\hline & (1) & (2) & (3) & (4) & (5) & (6) \\
\hline & OLS & OLS & OLS & 2SLS & 2SLS & 2SLS \\
\hline AvgLogDistance $_{\text {not }}$ & $-0.478 * * *$ & $0.319 * * *$ & $-2.690^{*}$ & $-0.552 * *$ & $0.330 * *$ & -0.405 \\
\hline Observations & 48 & 48 & 48 & 48 & 48 & 48 \\
\hline AR p-value & - & - & - & 0.021 & 0.041 & 0.874 \\
\hline R-squared & 0.451 & 0.593 & 0.877 & 0.448 & 0.593 & 0.871 \\
\hline
\end{tabular}

Robust standard errors in brackets. Dependent variables: PG Exp. (Public Good Expenditures) = Share of state expenditures on education, public welfare, health, and hospitals in 2008; Oth. Exp. (Other Expenditures) = Share of state expenditures on government administration, interest on debt, and "other” in 2008; PG Prov. (Public Good Provision) = First principal component of "Smart State" Index (2005), \% of population with health insurance (2008-9), and log of hospital beds per capita

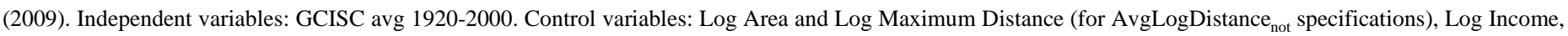
Log Population, \% College, Share of government employment, Racial dissimilarity, \% Urban, Regional dummies (all specifications). IV: centroid AvgLogDistance ${ }_{\text {not }}$ of population. AR p-value: $\mathrm{p}$-value from Anderson-Rubin (minimum distance) test. ${ }^{* * *} \mathrm{p}<0.01,{ }^{* *} \mathrm{p}<0.05,{ }^{*} \mathrm{p}<0.1$. 
Figure 1

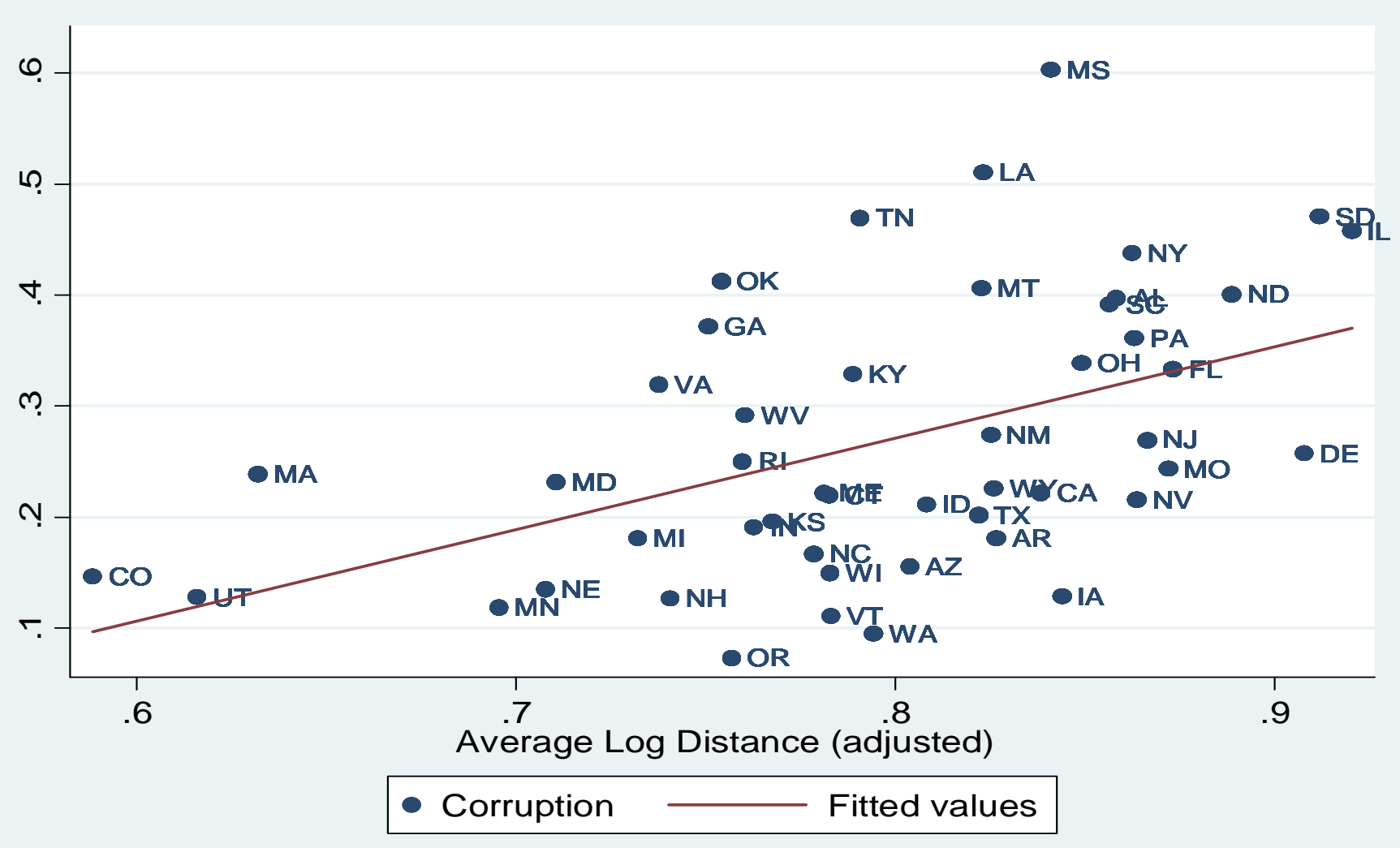

Notes: Corruption $=$ Federal convictions of public officials for corruption--related crime (average 1976-2002); Independent variables: AvgLogDistance ${ }_{\text {not }}$ (average 1920-1970)

Figure 2

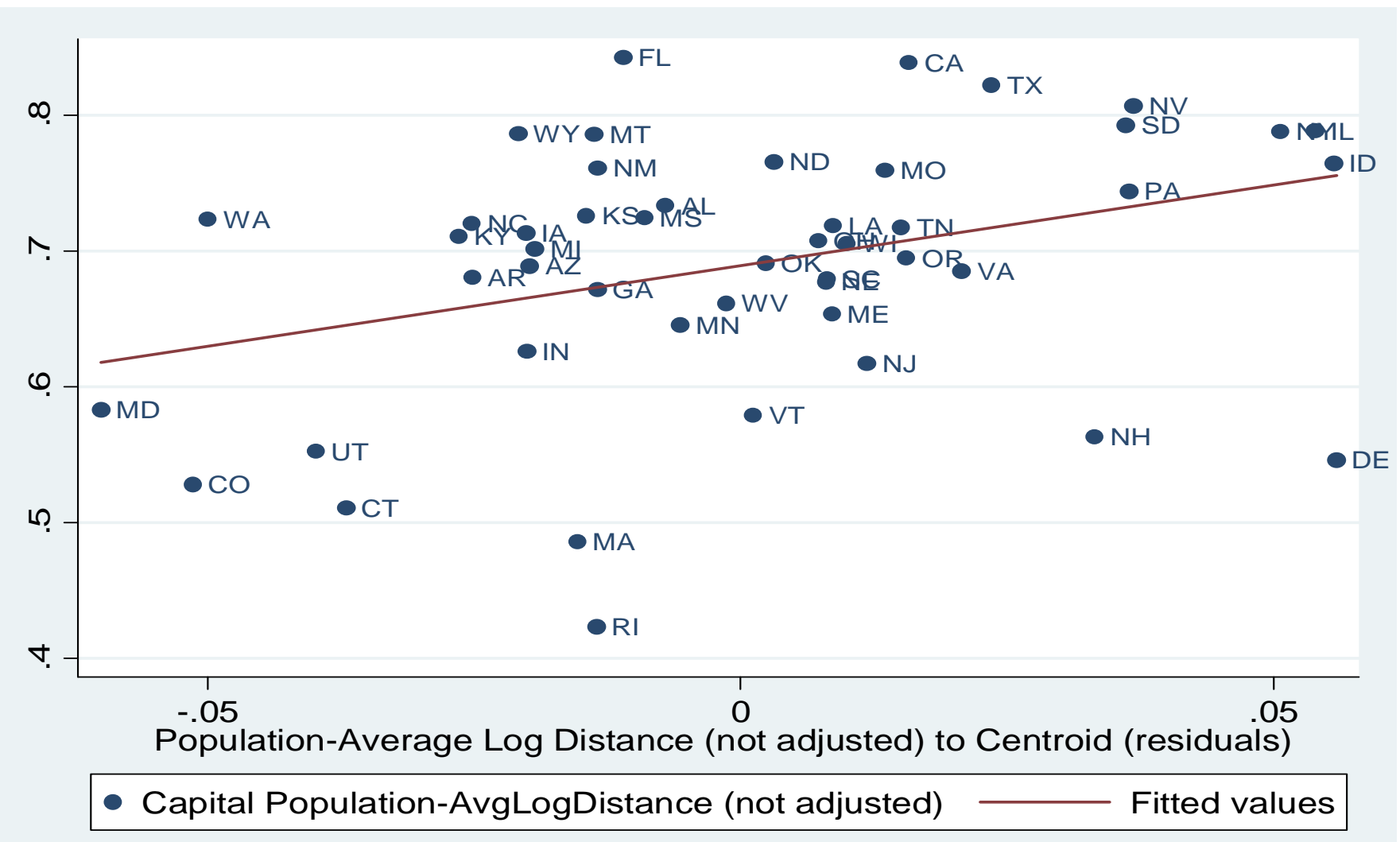

Notes: Capital Population-Average Log Distance’s (not adjusted) (average 1920-1970) residuals from regression of AvgLogDistance ${ }_{\text {not }}$ on Log Area and Log Maximum Distance. 
Table A2. Correlation over time of AvgLogDistance and AvgLogDistance adjusted

Table A1. Ranking of States by AvgLogDistance

\begin{tabular}{|c|c|c|c|}
\hline State & $\begin{array}{c}\text { AvgLog } \\
\text { Distance } \\
\text { (not } \\
\text { adjusted) } \\
\end{array}$ & State & $\begin{array}{c}\text { AvgLog } \\
\text { Distance } \\
\text { (adjusted) }\end{array}$ \\
\hline \multicolumn{4}{|c|}{10 most isolated } \\
\hline FLORIDA & 0.876 & ILLINOIS & 0.9281 \\
\hline NEVADA & 0.8589 & SOUTH DAKOTA & 0.921 \\
\hline CALIFORNIA & 0.852 & NEVADA & 0.9195 \\
\hline TEXAS & 0.8049 & FLORIDA & 0.9084 \\
\hline SOUTH DAKOTA & 0.8003 & DELAWARE & 0.8984 \\
\hline ILLINOIS & 0.7948 & NORTH DAKOTA & 0.8765 \\
\hline NEW YORK & 0.7853 & ALABAMA & 0.8658 \\
\hline WYOMING & 0.7851 & MISSOURI & 0.8608 \\
\hline MONTANA & 0.7763 & NEW YORK & 0.8599 \\
\hline NORTH DAKOTA & 0.7547 & SOUTH CAROLINA & 0.8526 \\
\hline \multicolumn{4}{|c|}{10 least isolated } \\
\hline NEW JERSEY & 0.6065 & NEW HAMPSHIRE & 0.7268 \\
\hline MINNESOTA & 0.6021 & MICHIGAN & 0.7236 \\
\hline VERMONT & 0.5798 & OKLAHOMA & 0.7202 \\
\hline MARYLAND & 0.5769 & MARYLAND & 0.7034 \\
\hline NEW HAMPSHIRE & 0.5522 & GEORGIA & 0.6957 \\
\hline DELAWARE & 0.5404 & COLORADO & 0.6831 \\
\hline UTAH & 0.5356 & MASSACHUSETTS & 0.6796 \\
\hline MASSACHUSETTS & 0.5222 & NEBRASKA & 0.6525 \\
\hline CONNECTICUT & 0.5137 & MINNESOTA & 0.6489 \\
\hline RHODE ISLAND & 0.4367 & UTAH & 0.5976 \\
\hline
\end{tabular}

\begin{tabular}{|c|c|c|c|c|c|c|c|c|c|}
\hline AvgLogDistance $_{\text {not }}$ & 1920 & 1930 & 1940 & 1950 & 1960 & 1970 & 1980 & 1990 & 2000 \\
\hline 1920 & 1 & & & & & & & & \\
\hline 1930 & 0.9960 & 1 & & & & & & & \\
\hline 1940 & 0.9937 & 0.9994 & 1 & & & & & & \\
\hline 1950 & 0.9829 & 0.9935 & 0.996 & 1 & & & & & \\
\hline 1960 & 0.9673 & 0.9832 & 0.9872 & 0.9967 & 1 & & & & \\
\hline 1970 & 0.9578 & 0.9766 & 0.9810 & 0.9917 & 0.9980 & 1 & & & \\
\hline 1980 & 0.9569 & 0.9755 & 0.9794 & 0.9859 & 0.9917 & 0.9964 & 1 & & \\
\hline 1990 & 0.9424 & 0.9629 & 0.9662 & 0.9702 & 0.9768 & 0.9857 & 0.9957 & 1 & \\
\hline 2000 & 0.9322 & 0.9539 & 0.9577 & 0.9628 & 0.9705 & 0.9811 & 0.9920 & 0.9987 & 1 \\
\hline AvgLogDistance $_{\text {adj }}$ & 1920 & 1930 & 1940 & 1950 & 1960 & 1970 & 1980 & 1990 & 2000 \\
\hline 1920 & 1 & & & & & & & & \\
\hline 1930 & 0.9917 & 1 & & & & & & & \\
\hline 1940 & 0.9873 & 0.9987 & 1 & & & & & & \\
\hline 1950 & 0.9697 & 0.9890 & 0.9937 & 1 & & & & & \\
\hline 1960 & 0.9412 & 0.9702 & 0.9777 & 0.9935 & 1 & & & & \\
\hline 1970 & 0.9242 & 0.9582 & 0.9662 & 0.9839 & 0.9960 & 1 & & & \\
\hline 1980 & 0.9125 & 0.9485 & 0.9562 & 0.9698 & 0.9833 & 0.9940 & 1 & & \\
\hline 1990 & 0.8809 & 0.9211 & 0.9280 & 0.9383 & 0.9542 & 0.9733 & 0.9913 & 1 & \\
\hline 2000 & 0.8639 & 0.9056 & 0.9131 & 0.9251 & 0.9422 & 0.9642 & 0.9844 & 0.9976 & 1 \\
\hline AvgLogDistance $_{\text {adj }} \backslash$ AvgLogDistance $_{\text {not }}$ & 1920 & 1930 & 1940 & 1950 & 1960 & 1970 & 1980 & 1990 & 2000 \\
\hline 1920 & 0.5703 & 0.578 & 0.5813 & 0.6064 & 0.6068 & 0.6018 & 0.5726 & 0.5492 & 0.5467 \\
\hline 1930 & 0.5782 & 0.5969 & 0.6024 & 0.6332 & 0.6405 & 0.6397 & 0.6114 & 0.5912 & 0.5902 \\
\hline 1940 & 0.5717 & 0.5926 & 0.5999 & 0.6332 & 0.6427 & 0.6423 & 0.6136 & 0.5927 & 0.5922 \\
\hline 1950 & 0.5423 & 0.5689 & 0.5784 & 0.6206 & 0.637 & 0.6383 & 0.6055 & 0.5820 & 0.583 \\
\hline 1960 & 0.5233 & 0.5563 & 0.5676 & 0.6158 & 0.6409 & 0.6463 & 0.614 & 0.5921 & 0.5942 \\
\hline 1970 & 0.5073 & 0.5436 & 0.5551 & 0.6042 & 0.6332 & 0.6441 & 0.6162 & 0.6002 & 0.6045 \\
\hline 1980 & 0.4962 & 0.5338 & 0.5452 & 0.5912 & 0.6210 & 0.6365 & 0.6171 & 0.6096 & 0.6157 \\
\hline 1990 & 0.4674 & 0.5079 & 0.5185 & 0.5613 & 0.5927 & 0.6142 & 0.6036 & 0.6082 & 0.6177 \\
\hline 2000 & 0.4450 & 0.4865 & 0.4976 & 0.5414 & 0.5738 & 0.5972 & 0.5880 & 0.5958 & 0.6088 \\
\hline
\end{tabular}

